\title{
CREB decreases astrocytic excitability by modifying subcellular calcium fluxes via the sigma-1 receptor
}

\author{
Authors: A. Eraso-Pichot ${ }^{1}$, R. Larramona-Arcas ${ }^{1 \#}$, E. Vicario-Orri ${ }^{1}{ }^{\#}$, R. Villalonga ${ }^{1}$, L. Pardo $^{1}$, E. Galea $^{1,2}{ }^{*}$, R. $^{*}$ \\ $\operatorname{Masgrau}^{1} *$
}

\begin{abstract}
Affiliations:
${ }^{1}$ Institut de Neurociències and Departament de Bioquímica i Biologia Molecular, Unitat de Bioquímica de Medicina, Edifici M, Universitat Autònoma de Barcelona, 08193 Bellaterra, Barcelona, Catalonia, Spain

${ }^{2}$ Institució Catalana De Recerca I Estudis Avançats (ICREA), Passeig Lluís Companys 23, 08010, Barcelona, Catalonia, Spain.

*Corresponding author. E-mails: roser.masgrau@uab.cat, galea.inc@ gmail.com. Telephone: +34 935814278; +34 935868143. Fax: +34935811573.

$\dagger$ Present address: Department of Neurosciences, School of Medicine, University of California, 9500 Gilman Dr, La Jolla, CA 92093, USA.

\# equal contribution
\end{abstract}

\begin{abstract}
Astrocytic excitability relies on cytosolic calcium increases as a key mechanism whereby astrocytes contribute to synaptic transmission and hence learning and memory. While it is a cornerstone of neurosciences that experiences are remembered because transmitters activate gene expression in neurons, long-term adaptive astrocyte plasticity has not been described. Here we investigated whether the transcription factor CREB mediates adaptive plasticity-like phenomena in astrocytes. We found that activation of CREB-dependent transcription reduced the calcium responses induced by ATP, noradrenaline or endothelin-1. As to the mechanism, expression of VP16CREB, a constitutively active CREB mutant, had no effect on basal cytosolic calcium levels, extracellular calcium entry or calcium mobilization from lysosomal-related acidic stores. Rather, VP16-CREB up-regulated sigma-1 receptor expression thereby increasing the release of calcium from the endoplasmic-reticulum and its uptake by mitochondria. Sigma-1 receptor was also upregulated in vivo upon VP16-CREB expression in astrocytes. We conclude that CREB decreases astrocyte responsiveness by increasing calcium signalling at the endoplasmicreticulum-mitochondria interface, which might be an astrocyte-based form of long-term depression.
\end{abstract}

Key Words: Calcium signalling, endoplasmic reticulum, mitochondria, mitochondria-associated membranes, MCU, VP16-CREB, CEPIA indicators. 
Acknowledgments: This research was funded by grants BFU2010-21921 and BFU2012-38844 from the Ministerio de Economía y Competitividad, Gobierno de España (Co-funded with European Regional Development's Fund, FEDER), and grants 2005SGR-00719 and 2014SGR-00984 from the Generalitat de Catalunya AGAUR. Abel Eraso is a recipient of the fellowship FPU13/05377 from the Ministerio de Educación, Cultura y Deporte, Gobierno de España and Raquel Larramona recipient of a fellowship from La Marató de TV3 (TV3-20141430). We thank Dr. Grant Churchill for providing us with Ned-19 and for critical reading of the manuscript and Cristina Gutiérrez for assistance in tissue culture.

\section{Abreviations:}

ER, endoplasmic reticulum

$\mathrm{IP}_{3}$, inositol 1,4,5-trisphosphate

CRE, cAMP regulatory element

CREB, cAMP regulatory element-binding protein

LTD, long-term depression

NA, noradrenaline

PKA, protein-kinase A

PKC, protein-kinase $\mathrm{C}$

MSK1, mitogen- and stress-activated protein kinase

RSK2, ribosomal protein S6 kinase

FBS, fetal bovine serum

ET-1, endothelin-1

Glu, glutamate

FCCP, carbonyl cyanide 4-(trifluoromethoxy)phenylhydrazone

GPN, Gly-Phe- $\beta$-Naphthylamide

MTT, 3-(4,5-dimethylthiazol-2-yl)-2,5-diphenyltetrazolium bromide

CEPIA, calcium-measuring organelle-entrapped protein indicators

PBS, phosphate buffered saline

NGS, normal goat serum

GPCR, Gq protein-coupled receptors

MCU, mitochondrial calcium uniporter

NAADP, nicotinic acid adenine dinucleotide phosphate

MAM, mitochondria-associated ER membranes

WT, wild-type 


\section{Introduction}

Calcium signals encode a wide range of physiological responses thanks to a diverse and extensive range of signalling components that can be activated upon receptor stimulation. In astrocytes, cytosolic calcium increases are largely the result of intracellular calcium mobilization due to activation of phospholipase C- $\beta$, with the consequent generation of inositol 1,4,5-trisphosphate $\left(\mathrm{IP}_{3}\right)$ and the activation of $\mathrm{IP}_{3}$ receptors in the endoplasmic reticulum (ER). Calcium release from lysosome-related acidic vesicles through the generation of the second messenger nicotinic acid adenine dinucleotide phosphate (NAADP) [1,2] and extracellular calcium entry also contribute to the final signature of each agonist-induced calcium responses in astrocytes [3]. Mitochondrial calcium uptake, which is coupled to $\mathrm{IP}_{3}$-induced calcium release [4], further shapes cytosolic calcium increases.

The notion that calcium signals are a physiologically relevant sign of responsiveness in astrocytes has been demonstrated both in vitro and in vivo [5], leading to the widely-accepted notion that astrocytes display an actionpotential independent but calcium-dependent "excitability". This feature allows them to couple neuronal activity to blood flow, maintain the blood-brain barrier, control ion, $\mathrm{pH}$ and transmitter homeostasis, provide metabolic support for neurons, and regulate synaptic transmission and memory-related processes [5-9]. It follows that astrocytic calcium signals may be tightly regulated such that their amplitude may be strengthened or diminished by neuronal or astrocytic activity.

CREB belongs to a large group of transcription factors of the basic leucine zipper domain family and binds to the cAMP regulatory element (CRE) of target genes. In neurons, CREB is a key regulator of synaptic plasticity in various forms including long-term potentiation (LTP), intrinsic plasticity and in some cases, long-term depression (LTD) [10-12], all of which manifest as changes in the threshold, amplitude or frequency of action potentials thus changing synaptic strength. CREB is activated by phosphorylation by a variety of kinases including PKA - the best characterised one - PKC, mitogen- and stress-activated protein kinase (MSK1) and ribosomal protein S6 kinase (RSK2) [13-15]. Moreover, in neurons, CREB can be synergistically activated by increases in intracellular calcium followed by CAMKII activation, and by cofactors such as CTRC [16]. We recently described that CREB is also expressed in astrocytes where it can be activated by neurotransmitters in a calcium-independent mechanism [13].

In the present study we posit that transmitter-dependent long-term changes in cell responsiveness requiring gene expression are not an exclusive property of neurons. To address this hypothesis we examined whether CREB regulates transmitter-induced calcium responses in astrocytes given the importance of calcium signalling in these cells. CREB-dependent transcription was activated with ATP or noradrenaline (NA) or by expression of VP16CREB, a constitutive active form of CREB widely used to study CREB-induced LTP and intrinsic plasticity in neurons [17]. Calcium responses were elicited thereafter with different transmitters including ATP, which has a prominent role in astrocyte physiology. CEPIA calcium dyes targeting subcellular compartments, pharmacological manipulation of signalling pathways and calcium imaging of single cells were used to dissect out organellar and molecular mechanisms. We found a novel link between CREB and calcium signals, mediated by the sigma-1 receptor at the mitochondria-associated membranes. 


\section{Materials and Methods}

Astrocyte culture

Astrocyte cultures were prepared from 1-day-old Sprague-Dawley rats following a previously described protocol [3]. Cells were plated in T150 flasks in DMEM medium supplemented with $10 \%$ fetal bovine serum (FBS), $20 \mathrm{U} / \mathrm{ml}$ penicillin, and $20 \mu \mathrm{g} / \mathrm{ml}$ streptomycin, and incubated at $37^{\circ} \mathrm{C}$ in a humidified atmosphere containing 5\% $\mathrm{CO}_{2}$. After reaching confluence, microglia were removed with mechanical shaking, and pure secondary astrocytes were seeded on new plates in the same medium.

\section{Adult astrocyte cultures}

Adult astrocyte cultures were prepared from 8-week-old Sprague-Dawley rats. In brief, rats were sacrified and cerebral cortices isolated. After removing meninges, cortices were incubated with papain $(2 \mathrm{U} / \mathrm{ml})$ and DNase (10 U/ml) for $15 \mathrm{~min}$ at $37^{\circ} \mathrm{C}$. Cell suspension was gentle triturated through a Pasteur pipette and filtered through a $22 \mu \mathrm{M}$ nylon mesh. Cells were collected by centrifugation at $500 \mathrm{~g}$ and plated into 24-well plates in DMEM/F12 medium supplemented with $10 \% \mathrm{FBS}, 20 \mathrm{U} / \mathrm{ml}$ penicillin, and $20 \mu \mathrm{g} / \mathrm{ml}$ streptomycin, and incubated at $37^{\circ} \mathrm{C}$ in a humidified atmosphere containing $5 \% \mathrm{CO}_{2}$. The medium was replaced every 2 days and the cultures were used at 8-15 days.

\section{Animal Model}

Transgenic mice with targeted expression of VP16-CREB in astrocytes conditional to gliosis (Gfa2tTa/TetO-VP16-CREB mice) [18] were used. They were kept under standard laboratory conditions (food and water ad libitum, $22 \pm 2^{\circ} \mathrm{C}$, a $12 \mathrm{~h}$ dark/light cycle, and 50-60\% humidity and no administration of doxycycline). All experimental procedures were approved by the Animal Welfare Committee of the Universitat Autònoma de Barcelona and the Generalitat de Catalunya and were in agreement with the European Union Laws for the protection of experimental animals.

\section{Activation of CREB-dependent transcription}

Activation in cultures with transmitters: We used ATP (adenosine 5'-triphosphate magnesium salt), L-(-)norepinephrine bitartrate (NA), endothelin-1 (ET-1) or a L-glutamic acid monosodium salt (Glu), all of them purchased from Sigma Aldrich.

Activation and inhibition in cultures with CREB constructs: We used three adenoviruses of serotype 5 harboring a constitutively active CREB (Ad5-VP16-CREB), a dominant negative CREB (Ad5-ACREB), or no CREB construct (Ad5-Null). The expression of the transgenes was mediated by the CMV promoter. Infections were carried out in DMEM with 1\% FBS using 1, 5, 30, and 100 multiplicity of infection (MOI). After 3 hours the medium was replaced by DMEM with $10 \%$ of FBS. All experiments were performed within $18 \mathrm{~h}-24 \mathrm{~h}$ after viral infections. No cellular death was detected up to $24 \mathrm{~h}$ after viral infections, as measured with 3-(4,5dimethylthiazol-2-yl)-2,5-diphenyltetrazolium bromide (MTT) reduction and Hoechst assays (data not shown). 
Activation in vivo: To induce expression of VP16-CREB in transgenic mice, we followed a protocol to induce gliosis. Five-seven month-old mice under tribromethanol anesthesia were cryolesioned with a dry ice pellet following a previously described protocol [18]. Buprenorfin at $0.1 \mathrm{mg} / \mathrm{Kg}$ was injected i.p. every $12 \mathrm{~h}$ until its sacrifice at 1-3 days after the cryolesion. Female and male mice were equally distributed among experimental groups.

\section{Detection of CREB-dependent transcription by Luciferase:}

Astrocytes were transfected with $1 \mu \mathrm{g}$ of plasmid pCRE-Luc and $0.5 \mu \mathrm{g}$ of plasmid pTK-Renilla in $1 \%$ FBScontaining DMEM using fugene 9 (Life Sciences). The plasmid pCRE-Luc (Promega) codifies for the luciferase gene under the control of a promoter that contains four CRE-sequences. After 48 hours luciferase luminescence was measured using the dual-luciferase reporter assay system (Promega) following the manufacturer's instructions. Transfection efficiency was normalised by co-transfection with the pTK-Renilla plasmid, which codifies for the renilla protein under a constitutive promoter.

\section{Stimulation and pharmacological manipulation of calcium signals}

To induce calcium responses we used ATP, NA or ET-1, all purchased from Sigma Aldrich. To manipulate different signalling pathways we used carbonyl cyanide 4-(trifluoromethoxy)phenylhydrazone (FCCP) and BD1047 from Tocris, EGTA, and Gly-Phe- $\beta$-Naphthylamide (GPN) from Sigma Aldrich. Ned-19 was provided by Dr. Grant Churchill of Oxford University. All these compounds were applied $20 \mathrm{~min}$ before calcium imaging.

\section{Intracellular calcium measurements}

Cells were loaded with fluo-4AM (Thermo Scientific) at $4 \mu \mathrm{M}$ and pluronic F-127 at $0.02 \%$ (Thermo Scientific) in Krebs Buffer with the following composition (in $\mathrm{mM}$ ): $113 \mathrm{NaCl}, 4.7 \mathrm{KCl}, 25 \mathrm{NaHCO}_{3}, 1.2 \mathrm{MgSO}_{4}$, 10 Hepes, $1.3 \mathrm{CaCl}_{2}$, and 10 glucose at $\mathrm{pH}$ 7.4. After $1 \mathrm{~h}$ in the dark at room temperature, the cells were washed with Krebs Buffer, and transmitter-induced calcium responses were measured with a Victor III fluorometer (Perkin Elmer) or an Eclipse TE2000-E fluorescence microscope (Nikon) (excitation at 466-496 nm, emission at 520-550 $\mathrm{nm}$ ). Microscope images were collected and analysed with the MetaMorph image processing software (Universal Imaging).

When fura-2AM was used, astrocytes were incubated with $2 \mu \mathrm{M}$ fura-2-AM (Thermo Scientific) and BSA in Krebs Buffer for $1 \mathrm{~h}$ in the dark at room temperature. After incubation, the coverslips were mounted in a static imaging chamber of an inverted epifluorescence Eclipse TE-2000U microscope (Nikon). The cells were excited at $340 \mathrm{~nm}$ and $380 \mathrm{~nm}$ using a monochromator (Cairn Research), and fluorescence emission at 495-520 nm was recorded with an ORCA-ER CCD camera (Hamamatsu). Images were processed and analysed with the MetaFluor image processing software (Universal Imaging). Cell-based calcium calibration assays were performed to estimate calcium concentrations according to the method of [19].

\section{Imaging of ER and mitochondrial calcium}

We used two plasmids encoding for calcium-measuring organelle-entrapped protein indicators (CEPIA), gifts from Masamitsu Lino, one for the ER (pCMV G-CEPIA-1ER, Addgene plasmid \# 58215) and the other for the mitochondria (pCMV CEPIA-3mt, Addgene plasmid \# 58219). $5 \mu \mathrm{g}$ of the CEPIA constructs were transfected 
using Amaxa nucleofector®. Two or three days after transfection with CEPIA plasmids, cells seeded on coverslips were mounted in a static chamber with Krebs Buffer in the epifluorescence Eclipse TE2000-U microscope stated above. The cells were excited at $476 \mathrm{~nm}$ and fluorescence emission was recorded at 510-560 nm. Images were analysed with the MetaFluor software.

Alternatively, in a particular set of experiments, astrocytes were loaded with the mitochondrial calcium dye rhod-2AM (Life technologies) at $10 \mu \mathrm{M}$ for $5 \mathrm{~min}$ at room temperature. The cells were excited at $552 \mathrm{~nm}$ and fluorescence emission was recorded at 570-640 nm. For each experiment, up to 60 single mitochondria were selected and mean of calcium increases were determined.

\section{Immunocytochemistry}

The cells were fixed with $4 \%$ paraformaldehyde in phosphate buffered saline (PBS) for 30 min at room temperature and permeabilised with PBS/0.1\% Triton X-100 for 15 min. Nonspecific binding blockade was performed with $1 \%$ normal goat serum (NGS, Thermo Scientific) in PBS followed by overnight incubation at $4^{\circ} \mathrm{C}$ with anti-GFAP (1/1,000 Dako) and anti-VP16 (1/500 Santa Cruz biotechnology) antibodies in 0.1\% NGS-PBS. After washing, the cells were incubated for $1 \mathrm{~h}$ with Alexa labelled secondary IgGs (1/1,000 in 0.1\%NGS-PBS, Thermo Scientific).

\section{Western blots}

The cells were lysed on ice with RIPA solution containing $50 \mathrm{mM}$ Tris- $\mathrm{HCl}, 150 \mathrm{mM} \mathrm{NaCl}, 0.1 \%$ Sodium Dodecyl Sulfate (SDS), 1 \% Nonidet P-40, protease inhibitor cocktail (Life Sciences), and phosphatase inhibitor cocktail (Sigma Aldrich). Protein concentrations were determined using Pierce BCA protein assay kit (Thermo Scientific). Equal amounts of protein $(15-30 \mu \mathrm{g})$ were subjected to SDS 8-15\% polyacrylamide gel electrophoresis and transferred to methanol-activated polyvinylidene fluoride membranes (Life Sciences). The membranes were blocked in $0.1 \%$ Tween 20-Tris buffer solution (TTBS) containing 5\% milk for $1 \mathrm{~h}$ and incubated overnight with primary antibodies: 1/1,000 sigma-1 receptor (Thermo Scientific), 1/500 VP16 (Santa Cruz Biotechnology), 1/2000 mitochondrial calcium uniporter (MCU, Abcam), 1/50,000 GAPDH (Thermo Scientific) and 1/20,000 $\beta$-Actin (Sigma Aldrich), diluted in 1\% BSA-TTBS. Peroxidase-conjugated goat anti-rabbit and anti-mouse (Thermo Scientific) were used as secondary antibodies at $1 / 10,000$ for $1 \mathrm{~h}$ at RT. The bands were detected with an enhanced chemiluminescence detection kit (ECL) and developed by autoradiography on X-ray film (AGFA).

\section{Quantitative PCR}

Total RNA extraction was done using TRIZOL reagent following manufacturer's instructions. Once purified, the mRNA was reverse-transcribed with RevertAid Reverse Transcriptase. Briefly, a reaction mix containing $1 \mu \mathrm{g}$ RNA, $2 \mu \mathrm{M}$ random hexamer primers, $2 \mu \mathrm{M}$ Oligo(dT) ${ }_{18}$ Primers, $0.5 \mathrm{mM}$ dNTPs, $0.45 \mathrm{mM}$ 1,4-Dithiothreitol, 10 U RNAseOut and $200 \mathrm{U}$ RevertAid Reverse Transcriptase was incubated at $25^{\circ} \mathrm{C}$ for $10 \mathrm{~min}, 42^{\circ} \mathrm{C}$ for $60 \mathrm{~min}$, and $72^{\circ} \mathrm{C}$ for $10 \mathrm{~min}$. All reagents were purchased from Thermo Scientific. After RNA reverse transcription, the resulting samples at 1:25 or 1:100 dilutions were amplified in an Applied Biosystems 7500 Fast system using TaqMan reagents for SigmaRl, Mcu, Tbp and Gapdh genes (Thermo Scientific). We used LinRegPCR software to obtain average PCR efficiencies for each gene and then compared the $\mathrm{Cq}$ values with the comparative $\mathrm{Cq}$ method 
[20]. Gene expression of sigma-1 receptor and $M c u$ in cultures were normalised to Gapdh and Mcu expression, respectively. In samples from mice, total mRNA extraction was performed after animals were sacrificed and the injured hemisphere was excised using a brain matrix as described in [18]; the expression of sigma-1 receptor was normalised to Tbp expression

\section{Statistical analysis}

Data are expressed as the mean \pm SEM of a minimum of three independent experiments. Two datasets were compared using Student's $t$ test, whereas multiple groups were analysed using ANOVA and a Dunnet post-test if all groups were compared to control, or a Turkey post-test when all groups were compared to each other.

\section{Results}

\section{Activation of CREB-dependent transcription regulates calcium signals}

To determine whether CREB changes astrocyte calcium signalling we used an experimental paradigm with two sequential interventions. The first one was applied to induce CREB-dependent transcription and consisted of transmitters (NA, ATP) or virally transduced VP16-CREB, a constitutively active form of CREB previously used in neurons [17] and other cell types [21,22]. The second intervention was aimed at directly examining excitability. To this end, we administered ATP, NA, or ET-1, three transmitters that are agonists of Gq protein-coupled receptors (GPCR), thereby activating the main intracellular calcium signalling pathways in astrocytes.

We previously showed that long-term incubation with $10 \mu \mathrm{M}$ NA or $100 \mu \mathrm{M}$ ATP, but not with $100 \mu \mathrm{M}$ glutamate, activated astrocytic CREB by an atypical PKC-dependent, calcium-insensitive mechanism [13]. In the present study, we resorted to 1-h pulses with the transmitters followed by a 5-h wait before the second stimulus to prevent alterations of calcium responses due to receptor desensitization. Calcium responses were examined with fluorimetry using the calcium dye fluo-4AM (Fig. 1a). Of note, agonist concentrations and duration of stimulation were set to achieve maximal CREB activation in our cultures while mimicking an activity-driven CREB activation in vivo. For example, micromolar concentrations of NA might be achieved under particular physiological and/or pathological conditions in vivo [23, 24]. At these concentrations, NA activates $\alpha$ - and $\beta$-adrenergic receptors [23], the latter being linked to gene transcription and plasticity in neurons [25].

Pulses of NA and ATP were able to stimulate CREB as shown with CRE-containing luciferase reporter assays, while glutamate (Glu) and ET1 had no effect (Fig. 1b). Accordingly, only CREB-activating neurotransmitters induced down-regulation of calcium responses (12-39\%), suggesting that CREB mediates the actions of ATP and NA (Fig. 1c-h). Interestingly, the decreased calcium response was observed with all the transmitters tested (NA, ATP and ET-1) (Fig. 1c-h), suggesting that CREB targets core pathways of calcium signalling in astrocytes. In ensuing experiments we used $10 \mu \mathrm{M}$ NA as the first stimulus and $100 \mu \mathrm{M}$ ATP as the second. We selected the former because NA is a prototypical neurotransmitter acting through volume transmission and modulates the capacity of astrocytes to respond to local neuronal activity [26]. We selected ATP as the second stimulus because ATP drives intra- and intercellular calcium waves in astrocytes in cultures and in vivo, and is involved in many important physiological events [27-30]. Time-course analysis revealed that the reduction of 
calcium responses was still present at $12 \mathrm{~h}$ but not at $24 \mathrm{~h}$ after incubation with NA (Fig. 2a-c), hence it was transient. Finally, we verified that the decreased response was due to CREB activation using virally-transduced ACREB, a well-known dominant negative construct of CREB [31]. $18 \mathrm{~h}$ after infection of cells with an empty viralvector (Null), ATP-induced calcium responses were smaller in cells pre-treated with NA; however, no differences were observed between NA and non-treated cells if astrocytes were infected with A-CREB (Fig. 2d-f). In other words, the presence of A-CREB abolished the NA-mediated reduction of ATP-induced calcium responses, confirming that it is a CREB-specific phenomenon.

Before examining whether VP16-CREB reproduced the effect of physiological transmitters on calcium excitability, we confirmed the expression of the transgene with immunocytochemistry and western blot (Fig. 3a-b). The first technique allowed us to calculate that around $85 \%$ of astrocytes were infected by the VP16-CREB viral vector. Next we examined the effect of VP16-CREB on excitability using different MOIs of the virus. Astrocytes expressing VP16-CREB showed smaller ATP-induced calcium responses (20-30\%) compared to astrocytes infected with the Null viral vector (Fig. 3d-e). The reduction of calcium responses was observed 18-24 hours after infection and was independent of the vector concentration, whereas astrocytes infected with the Null vector responded as non-infected astrocytes (data not shown). VP16-CREB also decreased calcium responses to 10 $\mu \mathrm{M}$ NA (Fig. 3f-g). Finally, we explored whether VP16-CREB expression changes basal intracellular calcium levels using the ratiometric calcium indicator fura-2AM. Astrocytes infected with the empty vector had a rest calcium concentration of $117 \pm 8 \mathrm{nM}$ whereas VP16-CREB expressing cells had $112 \pm 5 \mathrm{nM}$ (means of 3 independent experiments), indicating that CREB did not exert any effect on basal calcium levels.

Overall, this set of experiments demonstrates that CREB activation decreases transmitter-elicited calcium signals in astrocytes, while it does not interfere with basal calcium.

\section{Analysis of calcium fluxes}

We next studied the mechanism by which VP16-CREB regulates intracellular calcium responses, analyzing the contribution of calcium mobilization, extracellular calcium entry and calcium uptake mechanisms, in order to investigate if there is regulation of a specific signalling pathway or a general alteration of calcium homeostasis. As CREB does not abolish calcium responses but reduces them by $15-30 \%$, we first analysed extracellular calcium entry and intracellular calcium release from lysosomes, which have an important but not major role in ATP and NA-induced calcium responses [3]. We infected astrocytes with VP16-CREB or Null viral vectors at 1-5 MOI and followed calcium responses with real-time fluorescence microscopy after treating astrocytes with $0.5 \mathrm{mM}$ EGTA to chelate extracellular calcium, $50 \mu \mathrm{M}$ GPN, a lysosomal disruptor, or $100 \mu \mathrm{M}$ Ned-19, an inhibitor of the NAADP receptor [32]. All these pharmacological treatments diminished intracellular calcium responses in Null infected astrocytes, as previously described [3], but also in VP16-CREB expressing astrocytes (Fig. 3d and Fig. 4a-c). Therefore, the down-regulation of calcium by VP16-CREB compared to Null astrocytes was not altered (Fig. 4a-d). Thus, CREB does not appear to alter extracellular calcium entry or calcium mobilization from acidic vesicles.

We then evaluated calcium release from the ER using G-CEPIA1er, a new calcium protein indicator that specifically localizes in the ER [33]. After co-expression of G-CEPIA1er and VP16-CREB, the cells were treated 
with $100 \mu \mathrm{M}$ ATP (Fig. 4e). As shown in Fig. 4f-g, VP16-CREB increased calcium release from the ER. This unexpected result proves that CREB does not reduce purinergic or GPCR expression, nor is there receptor downregulation or desensitization; however the observation is paradoxical because greater calcium release from the ER would cause an increase in cytosolic calcium. Since this is not the case, we reasoned that either calcium from the ER is not released to the cytosol, or there is a mechanism of calcium extrusion/uptake potentiated by CREB. We thus focused on analyzing calcium uptake by the mitochondria. First, we recorded the cytosolic calcium increase induced by $100 \mu \mathrm{M}$ ATP after inhibition of mitochondrial calcium uptake with FCCP, an ionophore that transports protons through the inner mitochondrial membrane, and hence disrupts the electrogradient-driven calcium uptake. FCCP increased ATP-induced calcium responses so that VP16-CREB and Null astrocytes presented calcium responses of equal magnitude (Fig. 5a-b). Second, we directly measured mitochondrial calcium uptake using CEPIA3mt, a new low affinity green fluorescent mitochondrial calcium protein indicator [33] (Fig. 5c). VP16CREB astrocytes presented a greater mitochondrial calcium increase than Null astrocytes upon stimulation with $100 \mu$ M ATP (Fig. 5d-e), in accordance with the FCCP data. Similar results were obtained using rhod-2/AM, a low affinity calcium dye that is preferably entrapped in the mitochondria. Calcium increases in individual mitochondria were $2.89 \pm 0.7$ times higher in VP16-CREB than in Null-infected cells.

\section{The sigma-1 receptor mediates the effect of VP16-CREB}

Taken together, these data indicate that VP16-CREB increases both calcium release from the ER and mitochondrial calcium uptake. These data would be reconciled if CREB activation were potentiating ERmitochondria interaction, a process that appears to be key for several cellular functions including calcium signalling [34]. Indeed, calcium transfer from the ER to the mitochondria through mitochondria-associated ER membranes (MAM) is initiated by the release of calcium from the ER following the production of $\mathrm{IP}_{3}$ [34]. MAMs integrate many different proteins. Among these, sigma-1 receptors have been shown to have a CREB-binding consensus sequence and to interact with the $\mathrm{IP}_{3}$ receptor [35]. We therefore studied whether VP16-CREB expression leads to increased expression of sigma-1 receptor with real-time PCR and Western blot. VP16-CREB-expressing astrocytes do have greater sigma-1 receptor mRNA and protein content than Null-infected cells (Fig. 6a-b). We then examined if sigma-1 receptor up-regulation contributes to the CREB-mediated effects on calcium fluxes. Pretreatment with of the sigma-1 receptors inhibitor BD1047 at $10 \mu \mathrm{M}$ diminished the calcium release from the ER (Fig. 6c-d), and reduced mitochondrial calcium increases (Fig. 6e-f) in ATP-stimulated VP16-CREB-expressing astrocytes. All in all, the results provide evidence that the effects of VP16-CREB on calcium signalling can be mediated by the sigma-1 receptor and lend support to the following scenario: VP16-CREB raises the expression of the sigma-1 receptor thus amplifying the functional coupling between ER and mitochondria, increasing mitochondrial calcium uptake and thereby reducing cytosolic calcium.

Sigma-1 receptor in the ER membranes can interact with different proteins of the outer mitochondrial membrane facilitating the flux of calcium, which might then be driven to the mitochondrial matrix through the mitochondrial calcium uniporter (MCU). Very little is known about regulation of MCU at transcription levels [36,37]. We therefore checked if VP16-CREB was also changing MCU expression. As shown in Fig 7a and 7b, MCU is expressed in astrocytes but paradoxically, VP16-CREB diminished its expression both at the mRNA and 
protein level. We consider that this finding is in agreement with our previous observations that, in VP16-CREB expressing astrocytes, mitochondrial calcium uptake is increased but not to very high levels, therefore VP16-CREB induced MCU-downregulation might be a protective mechanism to avoid mitochondrial calcium overload and hence cell death. Moreover, the changed expression of MCU supports the notion that mitochondrial calcium uptake is exquisitely regulated by transmitter-induced gene expression.

\section{CREB-dependent transcription regulates calcium signals and sigma-1 receptor in adult astrocytes}

The first demonstration of the implication of neuronal CREB in synaptic and plasticity was obtained in simple model systems like primary cell cultures from Aplysia ganglia [38, 39]. Above we reported the effect on CREB on astrocyte plasticity using primary cultures from neonatal astrocytes. Next, we sought to confirm key findings in cultured astrocytes from adult rats. Following the protocol stated in Fig. 1a, NA induced CREB activation by $368.7 \pm 94.7 \%$ and this resulted in decreased ATP-induced calcium responses as shown in Fig. $8 \mathrm{a}$ and $8 \mathrm{~b}$, much resembling the results in postnatal astrocytes. Reduction of ATP-induced calcium signals to the same extent was also achieved 18-24 hours after VP16-CREB infection compared to Null-infected astrocytes (Fig. 8c-d). In this case, the VP16-CREB viral vector infected around 78\% of astrocytes. Finally, sigma-1 receptor was also upregulated upon VP16-CREB overexpression (Fig. 8e). We therefore checked if sigma-1 receptor is upregulated by CREB in vivo. To do so, we made use of transgenic mice where VP16-CREB is targeted to astrocytes. In such animals, CREB activation is driven by a gfap promoter and is not significantly increased in the forebrain in normal conditions (see [18] for a full characterization of the animals and VP16-CREB expression) but it is after a traumatic brain injury (cryolesion), which induces gliosis and hence activates the gfap promoter. Accordingly, as shown in Fig. 8f, sigma-1 receptor expression is slightly but not significantly different between wild-type (WT) and VP16CREB mice. Cryolesions upregulate sigma-1 receptor mRNA in both WT and VP16-CREB transgenic mice and, under such paradigm, VP16-CREB mice show a statistically significant higher expression of sigma-1 receptor compared to WT. Overall, these results suggest that VP16-CREB upregulates sigma-1 receptor in astrocytes in vivo.

\section{Discussion}

In the present study we provide evidence that transmitter-induced intracellular calcium responses, the basis of astrocytic excitability, are regulated by transmitter-triggered gene expression via the transcription factor CREB. Specifically, activation of CREB-dependent transcription in astrocytes by two transmitters, ATP and NA, or by a constitutively active CREB, reduces the calcium responses triggered by the GPCR agonists ATP, NA, and ET-1. The decrease of calcium responses is transient if the trigger of CREB-dependent transcription is transmitters given in pulses, consistent with the fact that transmitters produce a transitory activation of signalling pathways leading to CREB activation-namely CREB phosphorylation by kinases-while VP16-CREB bypasses such kinases and constantly activates CREB-dependent transcription. All in all, the data support the novel view that CREB regulates plasticity-like phenomena by targeting calcium signalling. Interestingly, CREB activation is independent of calcium in astrocytes [13], preventing self-depleting feedback negative loops. It will be of value to further extend 
our results with experimental approaches that contemplate different magnitude and temporal patterns of CREB activation resembling a range of physiological or pathological conditions.

As to mechanisms, VP16-CREB over-expression does not interfere with basal calcium concentration nor does it exert a wide alteration of GPCR or calcium-channel expression or activation, because there is no change in extracellular calcium entry or NAADP-driven calcium mobilization from acidic stores. Rather, studies with CEPIA-based organellar calcium dyes point to changes in calcium fluxes between ER and mitochondria as a central mechanism. Thus, we found that VP16-CREB enhances purinerigic-induced calcium release from the ER, increases mitochondrial calcium uptake, and enhances the expression of sigma-1 receptor, a protein interacting with $\mathrm{IP}_{3^{-}}$ receptors at the MAMs [34]. These observations might not be mere coincidence. First, the inhibition of mitochondrial calcium uptake with FCCP prevents CREB from decreasing ATP-induced calcium responses, suggesting that mitochondria are the main uptake or extrusion loci involved. Second, the inhibition of the sigma-1 receptor abolishes the increased ER-calcium release and lowers mitochondrial calcium uptake, demonstrating that sigma-1 receptors - whose gene has a CREB binding site [35] - mediates the effects of CREB. We also detected upregulation of sigma-1 receptor in cultured astrocytes from adult rats after infection with the VP16-CREB viral vector, and in transgenic mice with targeted activation of CREB in astrocytes. However, we cannot rule out the intervention of other CREB-dependent genes in the modulation of calcium responses in astrocytes.

Importantly, the ATP-mediated mitochondrial calcium increases potentiated by VP16-CREB do not represent mitochondrial calcium overload because no cell death was detected after VP16-CREB expression, during the experimental times used in this study. In this sense, the decrease in the expression of the mitochondrial calcium uptake channel, MCU, induced by CREB may be a protective homeostatic change secondary to a more efficient coupling ER-mitochondria and confirms recently published data showing that CREB binds to the MCU promoter in chicken lymphocytes although in this case there is upregulation of MCU [40]. The CREB-dependent mitochondrial calcium rises in astrocytes may potentiate physiological functions such as oxidative phosphorylation or glutamate recycling and replenishment since enzymes such as alpha-ketoglutarate, isocitrate dehydrogenases, pyruvate dehydrogenase phosphatase, and ATP synthase are activated by mitochondrial calcium [41-42]. Accordingly, sigma-1 receptor stimulation in cardiomyocytes has been shown to reinforce calcium transport from the sarcoendoplasmic reticulum to the mitochondria and increase ATP production [43]. Although some authors support the idea that astrocytes are exclusively glycolytic, they have functional mitochondria and are capable of oxidizing glucose, fatty acids [44], and glutamate after its uptake from the synaptic cleft [6]. Thus, an adaptive and finely gene-regulated modulation of mitochondrial calcium, and hence of tricarboxylic acid cycle and ATP production, may be more important to astrocyte physiology than previously thought.

It is noteworthy that CREB does not completely abolish intracellular calcium signalling in astrocytes but fine-tunes the response (i.e., decreases are 12-39\%), suggesting that CREB also regulates non-mitochondrial based mechanisms such as gliotransmission [28]. Thus far, extensive ex-vivo and in-vivo evidence implicates calciumdependent gliotransmission in the regulation of synaptic transmission [45-48] —albeit with some controversy [5] but there was no evidence linking calcium-based astrocyte excitability and long-term plasticity. To our knowledge, this is the first report demonstrating that astrocytes, like neurons, do have long-term and transient intrinsic 
plasticity-like phenomena or 'cellular' memory in terms of calcium responses. Although the idea of structural and functional plasticity of astrocytes has already been explored in other laboratories [49], previous reports dealt with short-term changes in gliotransmission (less than 30 minutes long), and these changes were, moreover, not mediated by a transcription factor and hence gene expression [50-51]. Because CREB reduces rather than increases astrocyte excitability, it appears that we might have discovered an LTD-like phenomena that may help memory consolidation by inducing a negative feedback loop that maintains neural networks in stable states or very long transients [52]. As noted in a recent review of 60 years of research in synaptic plasticity, the importance of memory and modulation in behaviour relies on the concept of plasticity per se rather than on the direction of the change in synaptic strength [53]. In any event, our results need further confirmation in vivo.

Finally, it is worth noting the therapeutic interest of the capacity of CREB to modulate calcium signals as these are involved in many and diverse physiological and long-term pathological events such as cardiac atrophy [54] or neuronal degeneration [55]. In astrocytes, calcium hyperactivity is a hallmark of epilepsy [27] and neurodegenerative diseases $[29,56]$. In addition, we have recently reported that the targeted activation of CREB in astrocytes is beneficial in a model of acute brain damage [18] and here we provide evidence that sigma-1 receptor is upregulated by CREB in such context. Accordingly, disruption of $\mathrm{IP}_{3}$ receptor-mediated calcium release and activation of sigma-1 receptors are beneficial in animal models of stroke [57, 58]. Therefore, reduction of calcium signalling in astrocytes may be among the beneficial mechanisms switched on by CREB in several acute and chronic brain pathologies.

In summary, two main conclusions can be drawn from the present study: 1) Calcium responses are regulated by transmitter-triggered CREB-dependent transcription, supporting the idea that not only neurons are endowed with plasticity-like phenomena, and 2) CREB-dependent transcription results in increased sigma-1 receptor expression and hence in a more efficient communication between ER and mitochondria. This may potentiate mitochondrial function, thus linking astrocyte energy metabolism and plasticity.

\section{References}

1. Churchill GC, Okada Y, Thomas JM, Genazzani AA, Patel S, Galione A. (2002) NAADP mobilizes Ca2+ from reserve granules, lysosome-related organelles, in sea urchin eggs. Cell 111:703-708. doi: 10.1016/S0092-8674(02)01082-6

2. Yamasaki M, Masgrau R, Morgan AJ, Churchill GC, Patel S, Ashcroft SJH, Galione A. (2004) Organelle Selection Determines Agonist-specific Ca2+ Signals in Pancreatic Acinar and beta Cells. J Biol Chem 279:7234-7240.

3. Barceló-Torns M, Lewis AM, Gubern A, Barneda D, Bloor-Young D, Picatoste F, Churchill GC, Claro E, Masgrau R (2011) NAADP mediates ATP-induced Ca2+ signals in astrocytes. FEBS Lett 585:2300-2306. doi: 10.1016/j.febslet.2011.05.062

4. Li H, Wang X, Zhang N, Gottipati MK, Parpura V, Ding S. (2014) Imaging of mitochondrial Ca2+ dynamics in astrocytes using cell-specific mitochondria-targeted GCaMP5G/6s: Mitochondrial Ca2+ uptake and 
cytosolic $\mathrm{Ca} 2+$ availability via the endoplasmic reticulum store. Cell Calcium 56:457-466. doi: 10.1016/j.ceca.2014.09.008

5. Bazargani N, Attwell D (2016) Astrocyte calcium signaling: the third wave. Nat Neurosci 19:182-189. doi: $10.1038 / \mathrm{nn} .4201$

6. Bélanger M, Magistretti PJ (2009) The role of astroglia in neuroprotection. Dialogues Clin Neurosci 11:281296. doi: $10.1038 / \mathrm{nrn} 1722$

7. Verkhratsky A, Nedergaard M, Hertz L (2014) Why are Astrocytes Important? Neurochem Res 40:389-401. doi: 10.1007/s11064-014-1403-2

8. Perea G, Sur M, Araque A (2014) Neuron-glia networks: integral gear of brain function. Front Cell Neurosci 8:378. doi: 10.3389/fncel.2014.00378

9. Zorec R, Horvat A, Vardjan N, Verkhratsky A (2015) Memory Formation Shaped by Astroglia. Front Integr Neurosci 9:56. doi: 10.3389/fnint.2015.00056

10. Byrne JH, Kandel ER (1996) Presynaptic facilitation revisited: state and time dependence. J Neurosci $16: 425-435$.

11. Deisseroth K, Bito H, Tsien RW (1996) Signaling from synapse to nucleus: Postsynaptic CREB phosphorylation during multiple forms of hippocampal synaptic plasticity. Neuron 16:89-101. doi: 10.1016/S0896-6273(00)80026-4

12. Benito E, Barco A (2010) CREB's control of intrinsic and synaptic plasticity: implications for CREBdependent memory models. Trends Neurosci 33:230-240. doi: 10.1016/j.tins.2010.02.001

13. Carriba P, Pardo L, Parra-Damas A, Lichtenstein MP, Saura CA, Pujol A, Masgrau R, Galea E. (2012) ATP and noradrenaline activate $\mathrm{CREB}$ in astrocytes via noncanonical $\mathrm{Ca} 2+$ and cyclic AMP independent pathways. Glia 60:1330-1344.

14. Deak M, Clifton AD, Lucocq JM, Alessi DR (1998) Mitogen- and stress-activated protein kinase-1 (MSK1) is directly activated by MAPK and SAPK2/p38, and may mediate activation of CREB. EMBO J 17:44264441. doi: 10.1093/emboj/17.15.4426

15. Xing J, Ginty DD, Greenberg ME (1996) Coupling of the RAS-MAPK pathway to gene activation by RSK2, a growth factor-regulated CREB kinase. Science 273:959-963. doi: 10.1126/science.273.5277.959

16. Altarejos JY, Montminy M (2011) CREB and the CRTC co-activators: sensors for hormonal and metabolic signals. Nat Rev Mol Cell Biol 12:141-151. doi: 10.1038/nrm3072

17. Barco A, Alarcon JM, Kandel ER (2002) Expression of constitutively active CREB protein facilitates the late phase of long-term potentiation by enhancing synaptic capture. Cell 108:689-703. doi: 10.1016/S00928674(02)00657-8

18. Pardo L, Schlüter A, Valor LM, Barco A, Giralt M, Golbano A, Hidalgo J, Jia P, Zhao Z, Jové M, PorteroOtin M, Ruiz M, Giménez-Llort L, Masgrau R, Pujol A, Galea E. (2016) Targeted activation of CREB in reactive astrocytes is neuroprotective in focal acute cortical injury. Glia 64:853-874. doi: 10.1002/glia.22969

19. Grynkiewicz G, Poenie M, Tsien RY (1985) A new generation of Ca2+ indicators with greatly improved fluorescence properties. J Biol Chem 260:3440-3450. doi: 3838314

20. Pfaffl MW (2001) A new mathematical model for relative quantification in real-time RT-PCR. Nucleic 
Acids Res 29:e45. doi: 10.1093/nar/29.9.e45

21. Reusch JE, Colton LA, Klemm DJ (2000) CREB activation induces adipogenesis in 3T3-L1 cells. Mol Cell Biol 20:1008-20. doi: 10.1128/MCB.20.3.1008-1020.2000

22. Rothem L, Stark M, Assaraf YG (2004) Impaired CREB-1 phosphorylation in antifolate-resistant cell lines with down-regulation of the reduced folate carrier gene. Mol Pharmacol 66:1536-43. doi: 10.1124/mol.104.004135

23. Atzori M, Cuevas-Olguin R, Esquivel-Rendon E, Esquivel-Rendon E, Garcia-Oscos F, Salgado-Delgado RC, Saderi N, Miranda-Morales M, Treviño M, Pineda JC (2016) Locus Ceruleus Norepinephrine Release: A Central Regulator of CNS Spatio-Temporal Activation? Front Synaptic Neurosci. doi: 10.3389/fnsyn.2016.00025

24. Mather S, Sakaki M, Harley CW (2000) Norepinephrine ignites local hot spots of neuronal excitation: How arousal amplifies selectivity in perception and memory. Behav Brain Sci 16:217-265.

25. Salgado H, Köhr G, Treviño M (2012) Noradrenergic "Tone” Determines Dichotomous Control of Cortical Spike-Timing-Dependent Plasticity. Sci Rep 2:1-7. doi: 10.1038/srep00417

26. Paukert M, Agarwal A, Cha J, Doze VA, Kang JU, Bergles DE (2014) Norepinephrine controls astroglial responsiveness to local circuit activity. Neuron 82:1263-1270. doi: 10.1016/j.neuron.2014.04.038

27. Carmignoto G, Haydon PG (2012) Astrocyte calcium signaling and epilepsy. Glia 60:1227-1233. doi: 10.1002/glia.22318

28. Zorec R, Araque A, Carmignoto G, Haydon PG, Verkhratsky A, Parpura V (2012) Astroglial excitability and gliotransmission: an appraisal of $\mathrm{Ca} 2+$ as a signalling route. ASN Neuro 4:103-119. doi: 10.1042/AN20110061

29. Delekate A, Füchtemeier M, Schumacher T, Ulbrich C, Foddis M, Petzold GC (2014) Metabotropic P2Y1 receptor signalling mediates astrocytic hyperactivity in vivo in an Alzheimer's disease mouse model. Nat Commun 5:5422. doi: 10.1038/ncomms6422

30. Khakh BS, Sofroniew M V (2015) Diversity of astrocyte functions and phenotypes in neural circuits. Nat Neurosci 18:942-952. doi: 10.1038/nn.4043

31. Ahn S, Olive M, Aggarwal S, Krylov D, Ginty DD, VInson C (1998) A dominant-negative inhibitor of CREB reveals that it is a general mediator of stimulus-dependent transcription of c-fos . Mol Cell Biol 18:967-977.

32. Naylor E, Arredouani A, Vasudevan SR, et al (2009) Identification of a chemical probe for NAADP by virtual screening. Nat Chem Biol 5:220-6. doi: 10.1038/nchembio.150

33. Suzuki J, Kanemaru K, Ishii K, M. Ohkura, Y. Okubo, M. Lino (2014) Imaging intraorganellar Ca2+ at subcellular resolution using CEPIA. Nat Commun 5:4153. doi: 10.1038/ncomms5153

34. Raturi A, Simmen T (2013) Where the endoplasmic reticulum and the mitochondrion tie the knot: The mitochondria-associated membrane (MAM). Biochim Biophys Acta - Mol Cell Res 1833:213-224. doi: 10.1016/j.bbamcr.2012.04.013

35. Zhang Y, Lv X, Bai Y, Zhu X, Wu X, Chao J, Duan M, Buch S, Chen L, Yao H (2015) Involvement of sigma-1 receptor in astrocyte activation induced by methamphetamine via up-regulation of its own expression. J Neuroinflammation 12:29. doi: 10.1186/s12974-015-0250-7 
36. He J, Shi W, Guo Y, Chai Z (2014) ERp57 modulates mitochondrial calcium uptake through the MCU. FEBS Lett 588:2087-2094. doi: 10.1016/j.febslet.2014.04.041

37. Shanmughapriya S, Rajan S, Hoffman NE, et al (2015) Ca2+ signals regulate mitochondrial metabolism by stimulating CREB-mediated expression of the mitochondrial Ca2+ uniporter gene MCU. Sci Signal 8:ra23. doi: 10.1126/scisignal.2005673

38. Dash PK, Hochner B, Kandel ER (1990) Injection of the cAMP-responsive element into the nucleus of Aplysia sensory neurons blocks long-term facilitation. Nature 345:718-721. doi: 10.1038/345718a0

39. Byrne JH, Kandel ER (1996) Presynaptic facilitation revisited: state and time dependence. J Neurosci $16: 425-435$

40. Denton RM, Mccormack JG (1980) On the role of the calcium transport cycle in heart and other mammalian mitochondria. FEBS Lett 119:1-8.

41. Jouaville LS, Pinton P, Bastianutto C, Rutter G a, Rizzuto R (1999) Regulation of mitochondrial ATP synthesis by calcium: evidence for a long-term metabolic priming. Proc Natl Acad Sci U S A 96:1380713812. doi: 10.1073/pnas.96.24.13807

42. Tarasov AI, Griffiths EJ, Rutter GA (2012) Regulation of ATP production by mitochondrial Ca2+. Cell Calcium 52:28-35. doi: 10.1016/j.ceca.2012.03.003

43. Tagashira H, Bhuiyan MS, Shioda N, Fukunaga K (2014) Fluvoxamine rescues mitochondrial Ca2 + transport and ATP production through $\sigma 1$-receptor in hypertrophic cardiomyocytes. Life Sci 95:89-100. doi: 10.1016/j.lfs.2013.12.019

44. Panov A, Orynbayeva Z, Vavilin V, Lyakhovich V (2014) Fatty acids in energy metabolism of the central nervous system. Biomed Res Int 2014:472459. doi: 10.1155/2014/472459

45. Serrano A, Haddjeri N, Lacaille J, et al (2006) GABAergic Network Activation of Glial Cells Underlies Hippocampal Heterosynaptic Depression. J. Neurosci 26:5370-5382. doi: 10.1523/JNEUROSCI.525505.2006

46. Henneberger C, Papouin T, Oliet SHR, Rusakov DA (2010) Long-term potentiation depends on release of Dserine from astrocytes. Nature 463:232-236. doi: 10.1038/nature08673

47. Takata N, Mishima T, Hisatsune C, et al (2011) Astrocyte calcium signaling transfmorms cholinergic modulation to cortical plasticity in vivo. J Neurosci 31:18155-18165. doi: 10.1523/JNEUROSCI.528911.2011

48. Navarrete M, Araque A (2010) Endocannabinoids potentiate synaptic transmission through stimulation of astrocytes. Neuron 68:113-126. doi: 10.1016/j.neuron.2010.08.043

49. Pirttimaki TM, Parri HR (2013) Astrocyte plasticity: implications for synaptic and neuronal activity. Neuroscientist 19:604-15. doi: 10.1177/1073858413504999

50. Perez-Alvarez A, Navarrete M, Covelo A, Martin ED, Araque A (2014) Structural and functional plasticity of astrocyte processes and dendritic spine interactions. J Neurosci 34:12738-44. doi: 10.1523/JNEUROSCI.2401-14.2014

51. Cheung G, Sibille J, Zapata J, Rouach N (2015) Activity-Dependent Plasticity of Astroglial Potassium and Glutamate Clearance. Neural Plast 2015:109106. doi: 10.1155/2015/109106 
52. Chaudhuri R, Fiete S (2015) Computational principles of biological memory. Nat Neurosci 19: 394-403. doi: $10.1038 / \mathrm{nn} .4237$

53. Sweatt JD (2016) Neural Plasticity \& Behavior - Sixty Years of Conceptual Advances. J Neurochem doi: $10.1111 /$ jnc. 13580

54. Hill JA, Olson EN (2008) Cardiac Plasticity. N. Engl. J. Med. 358, 1370-1380

55. Abeti R, Abramov AY (2015) Mitochondrial Ca2+ in neurodegenerative disorders. Pharmacol Res 99:377381. doi: 10.1016/j.phrs.2015.05.007

56. Kuchibhotla K V, Lattarulo CR, Hyman BT, Bacskai BJ (2009) Astrocytes in Alzheimer. Science 323:12111215. doi: 10.1126/science.1169096

57. Li H, Xie Y, Zhang N, Yu Y, Zhang Q, Ding S (2015) Disruption of IP3R2-mediated Ca2+ signaling pathway in astrocytes ameliorates neuronal death and brain damage while reducing behavioral deficits after focal ischemic stroke. Cell Calcium 58:565-576. doi: 10.1016/j.ceca.2015.09.004

58. Ruscher K, Wieloch $\mathrm{T}$ (2015) The involvement of the sigma-1 receptor in neurodegeneration and neurorestoration. J Pharmacol Sci 127:30-35. doi: 10.1016/j.jphs.2014.11.011 
a

b

CREB-dependent transcription

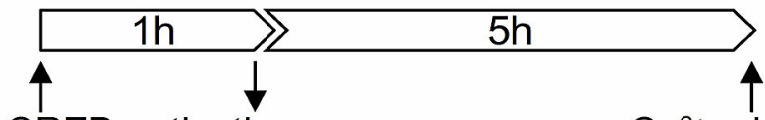

CREB-activating

transmitter

$\mathrm{Ca}^{2+}$ releasing transmitter

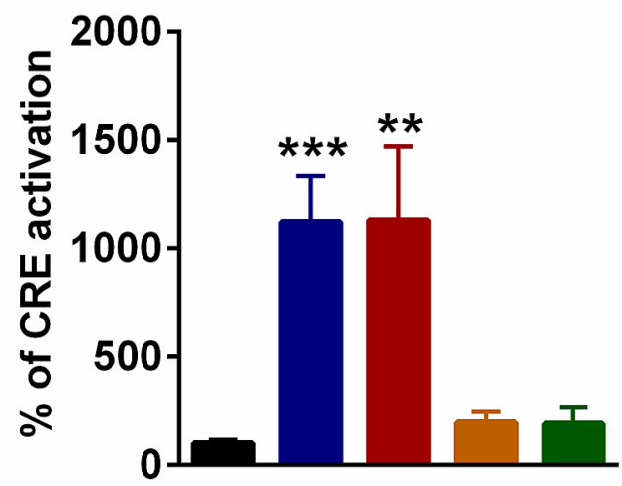

C

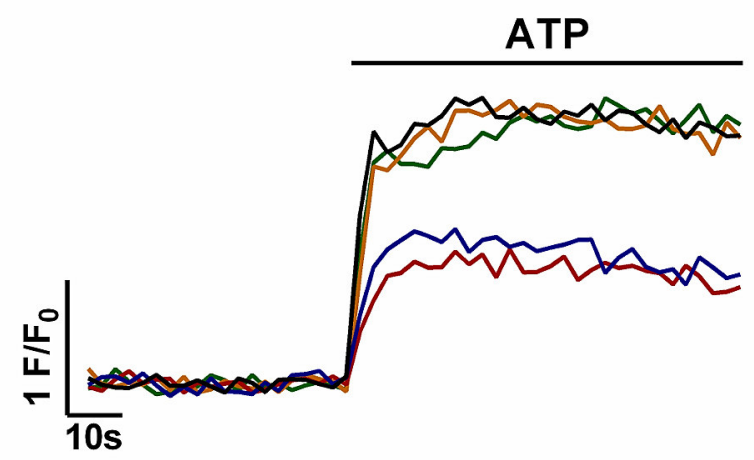

e

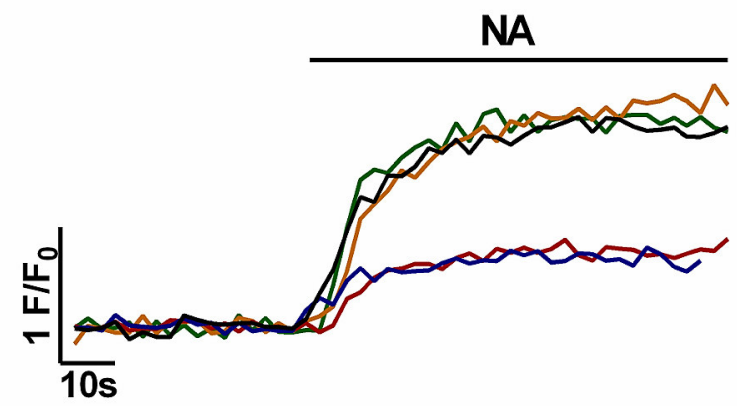

g

ET-1

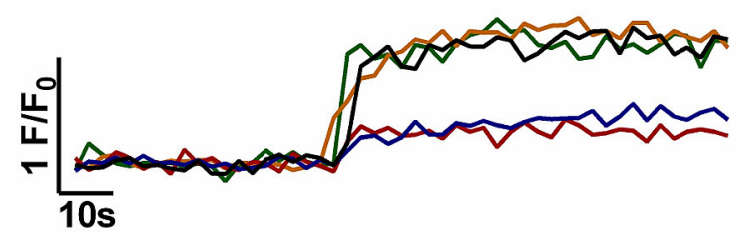

d

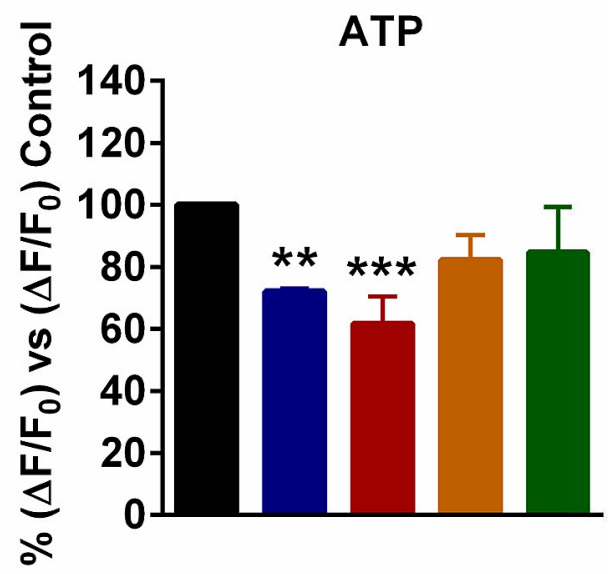

f

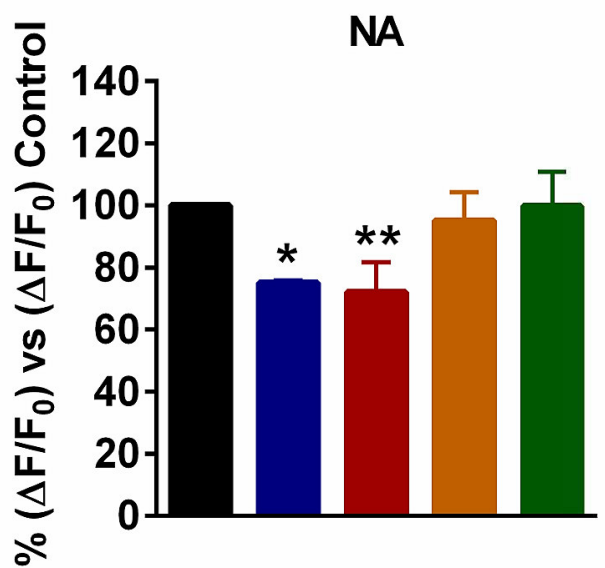

h

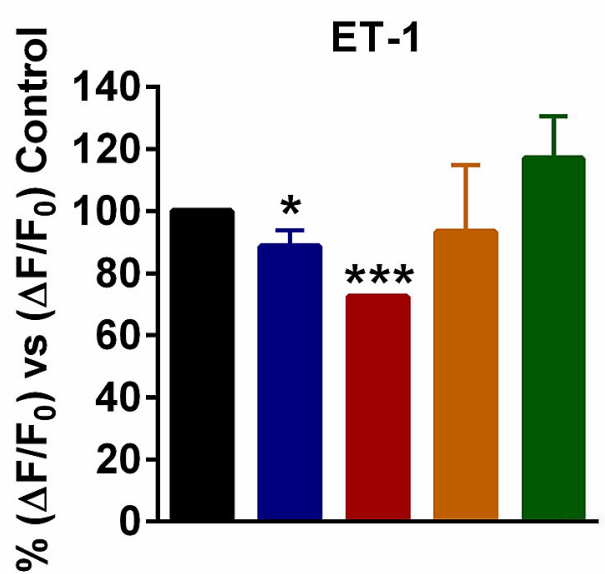




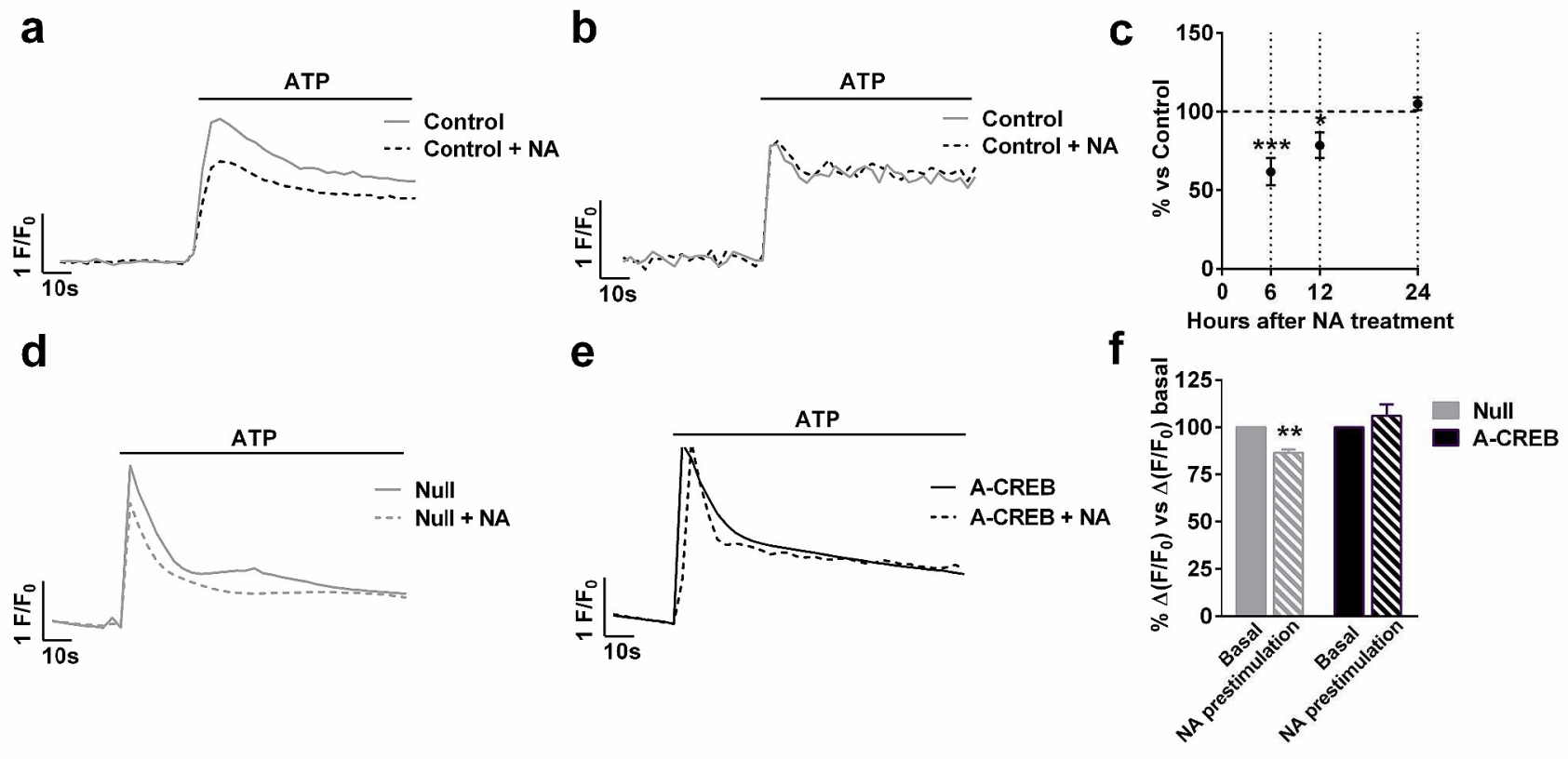


a

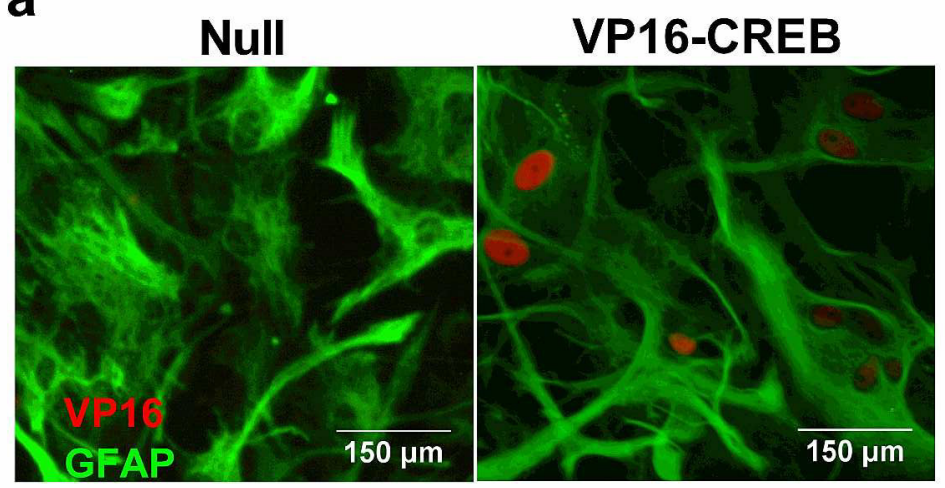

d

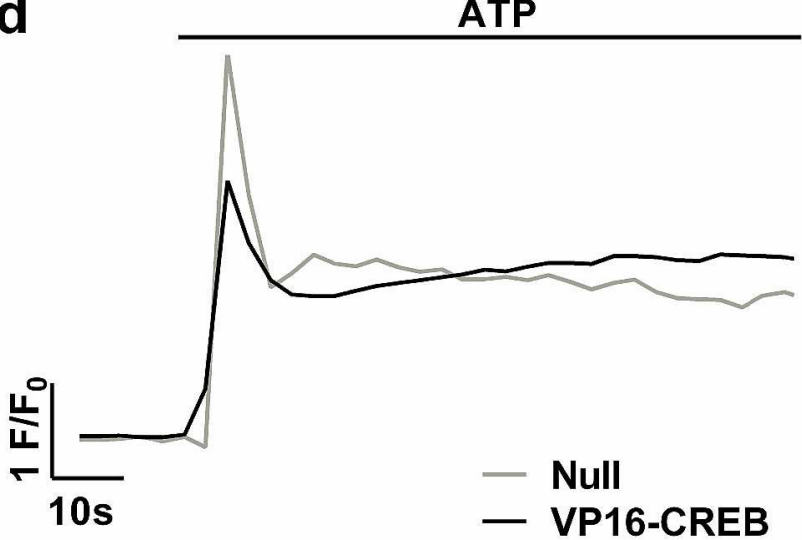

f

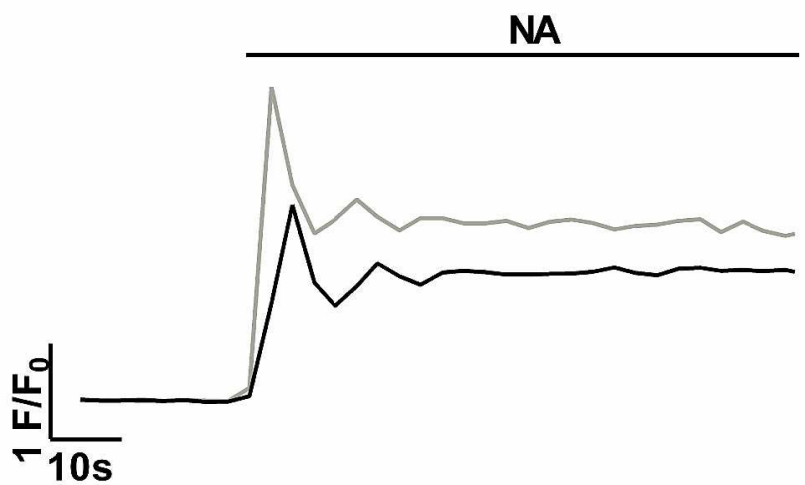

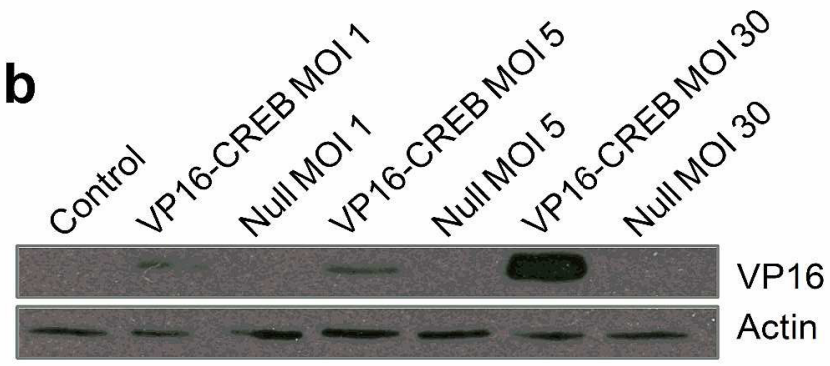

C

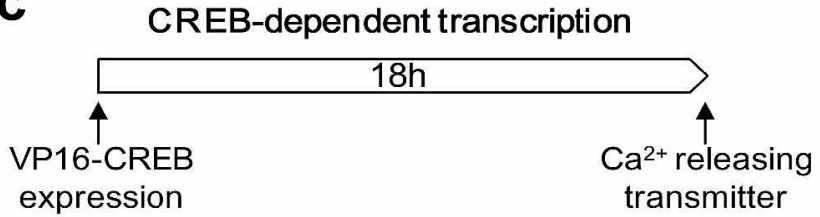

e

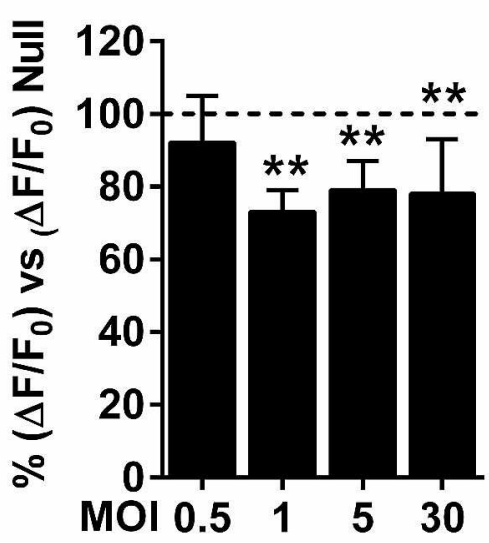

g

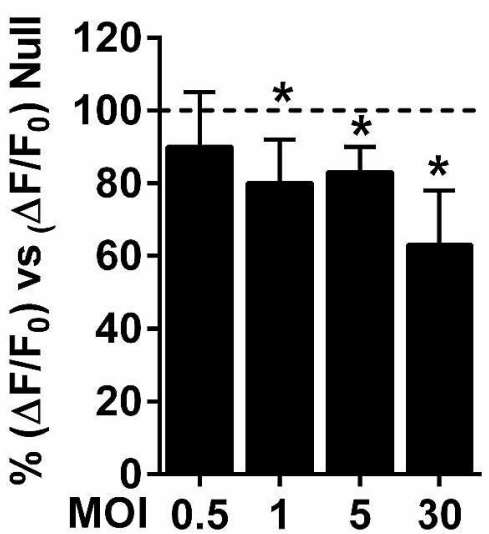


a

b
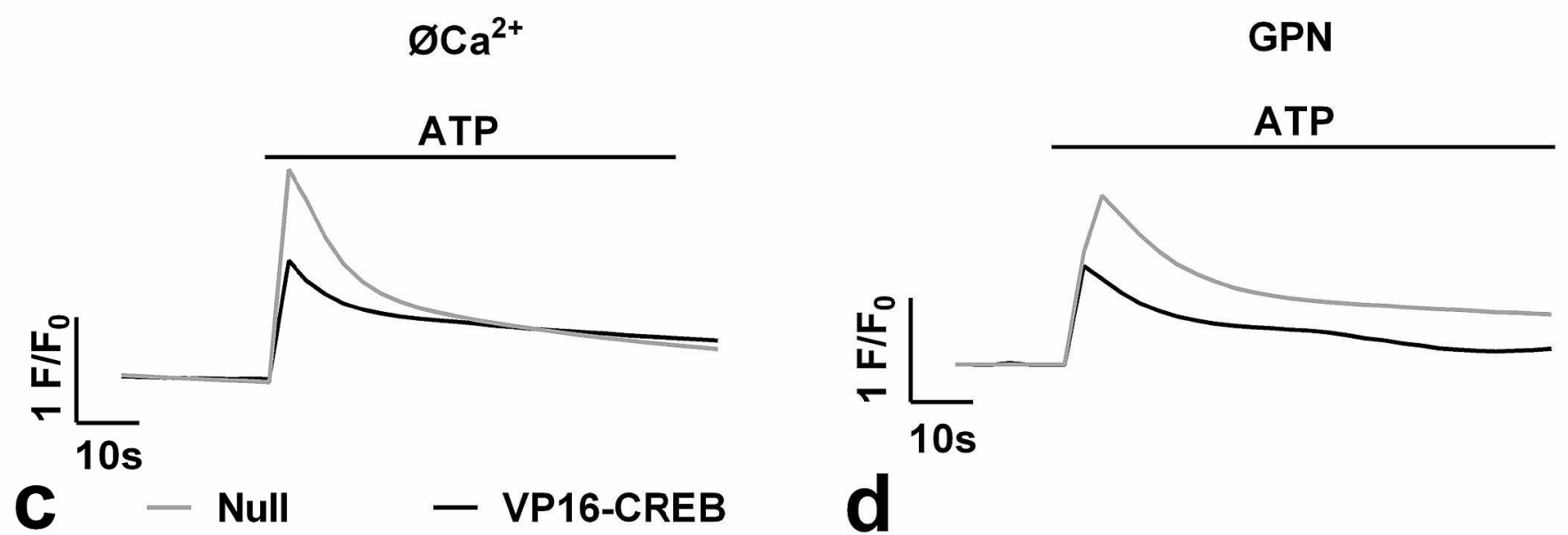

C - Null - VP16-CREB
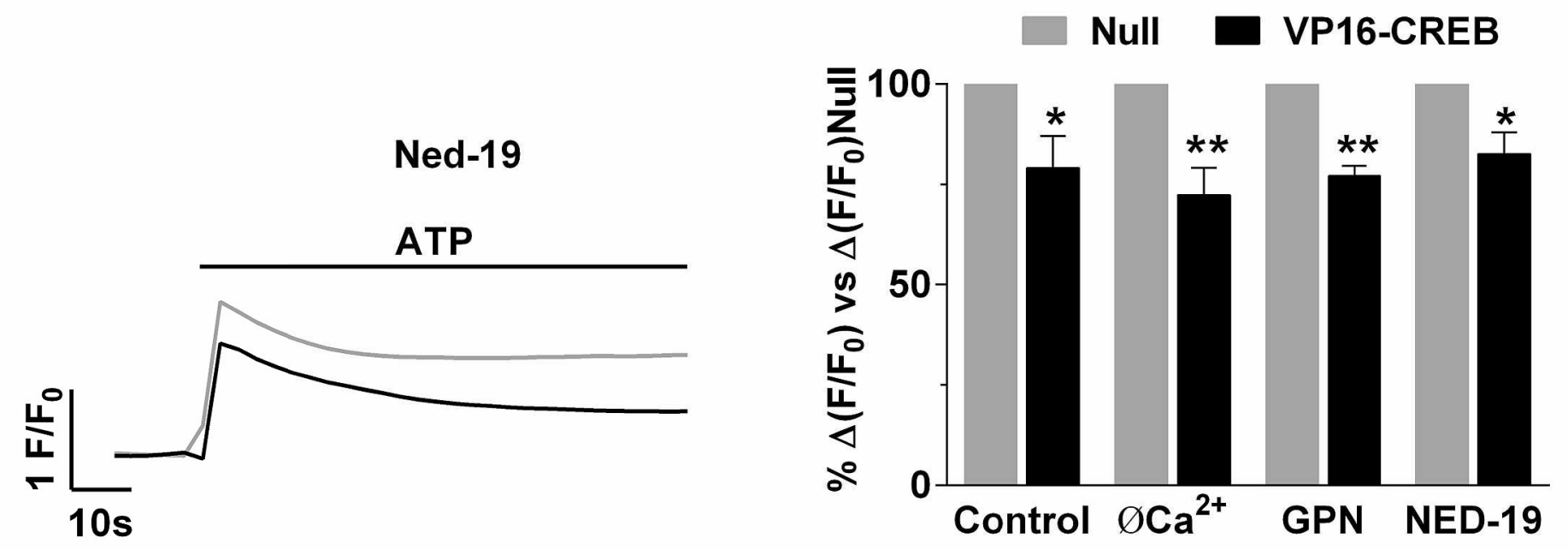

e
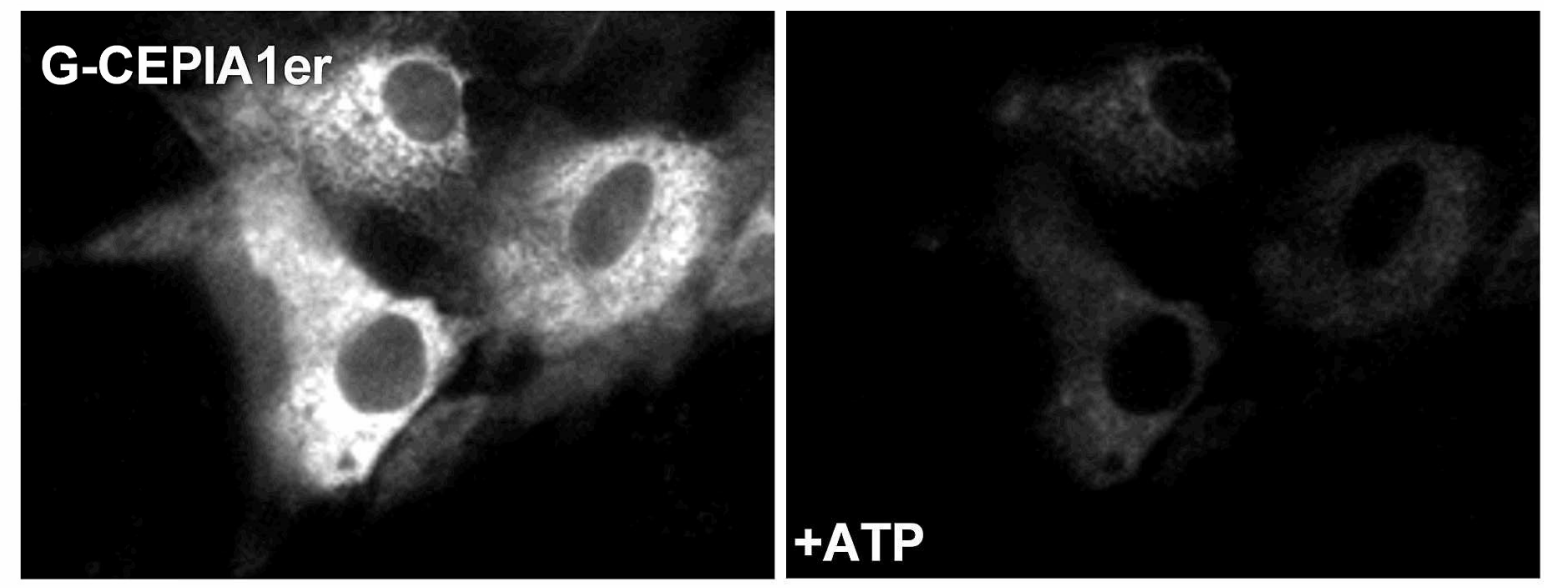

f

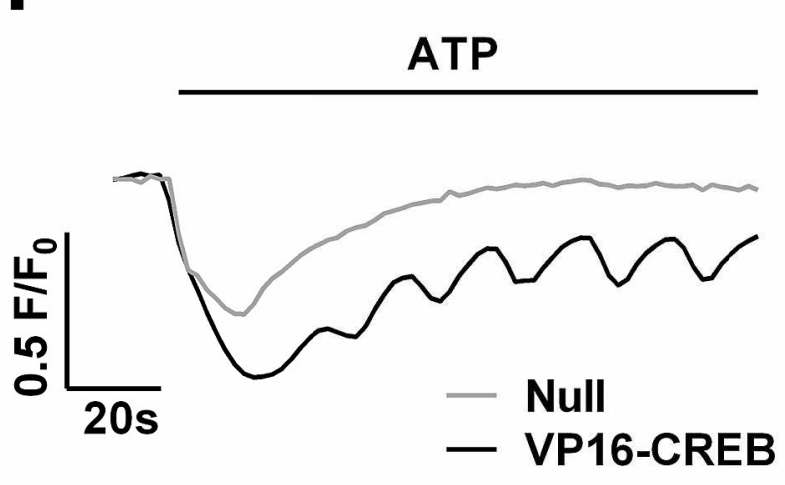

g

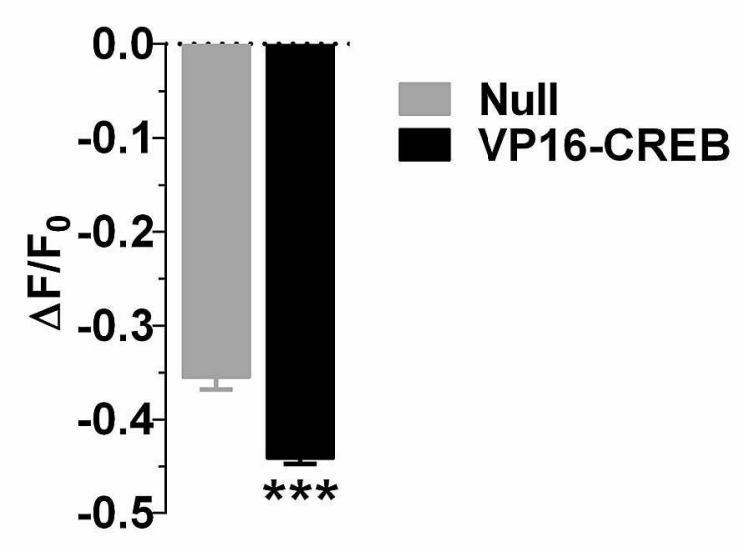


a

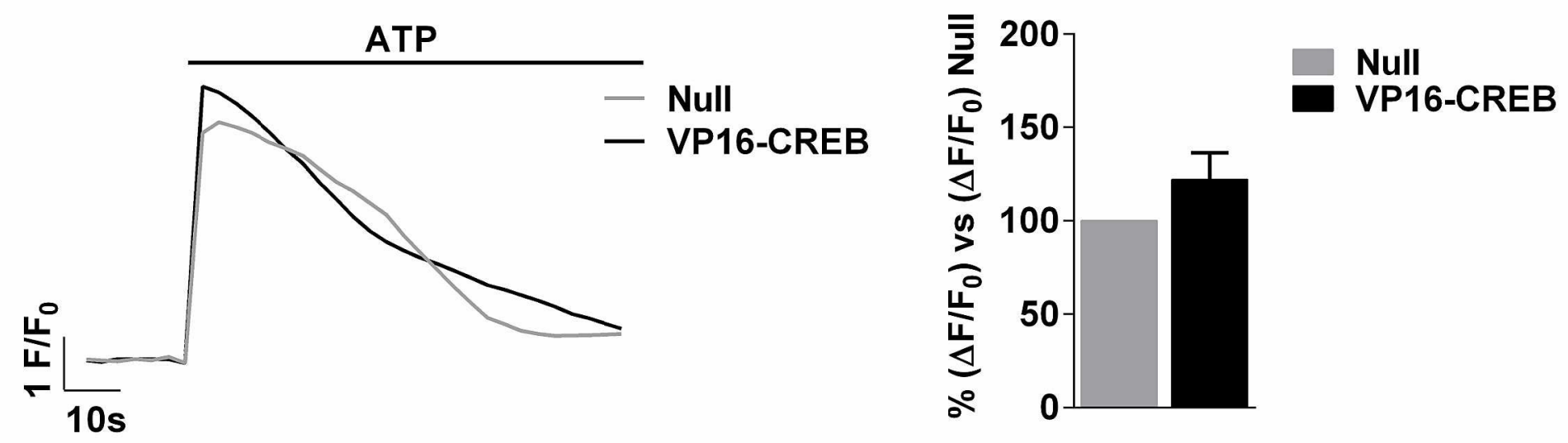

C
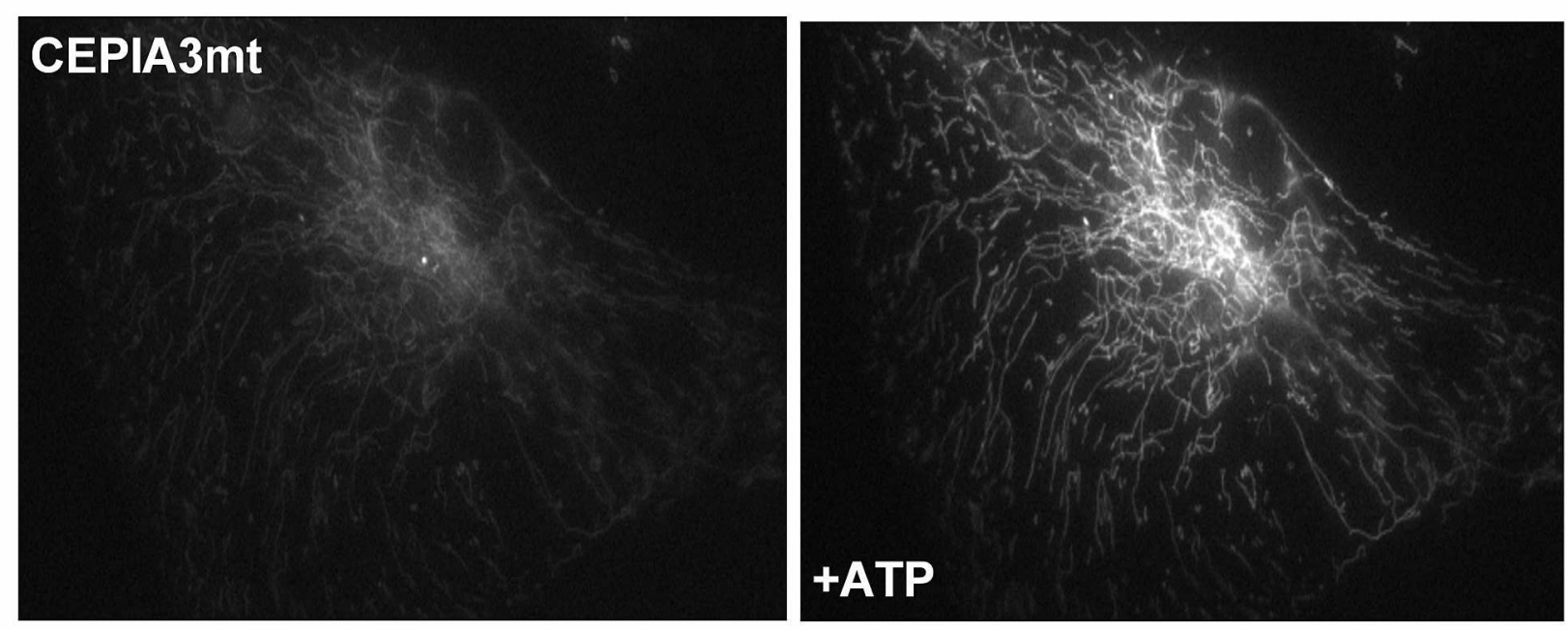

d

e
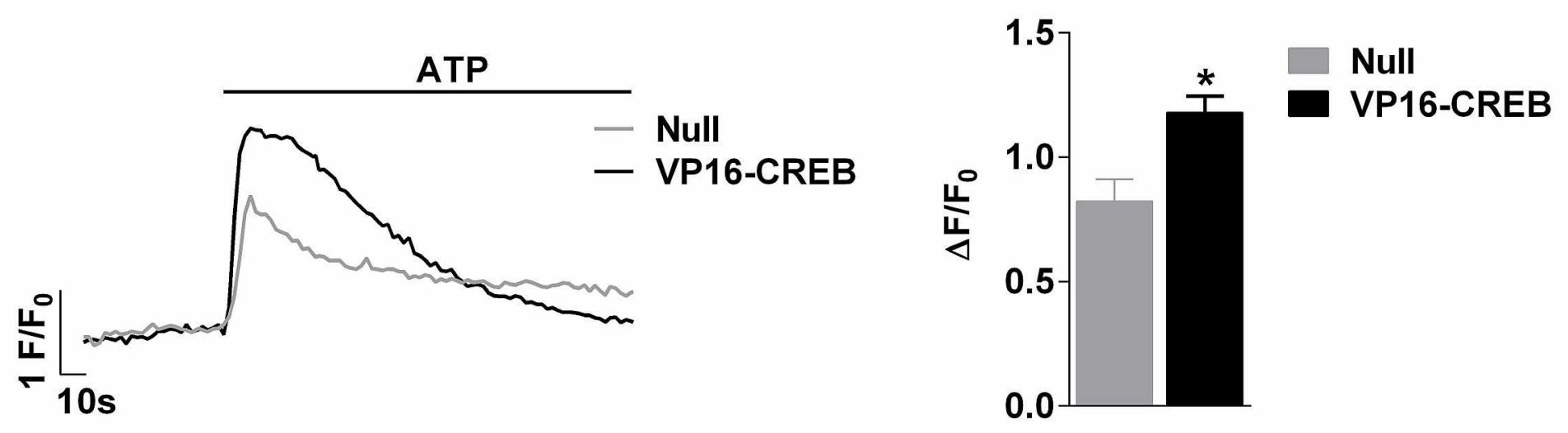
a

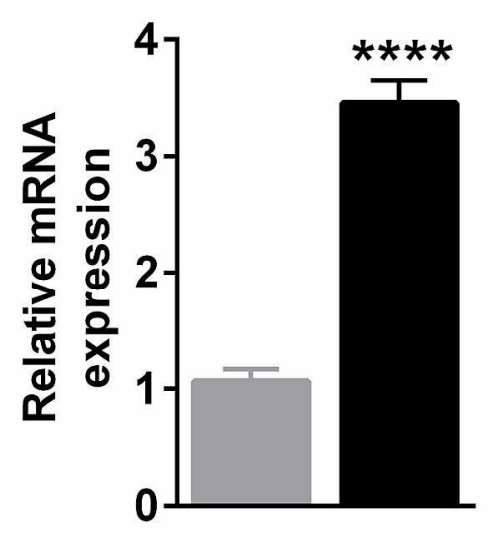

C

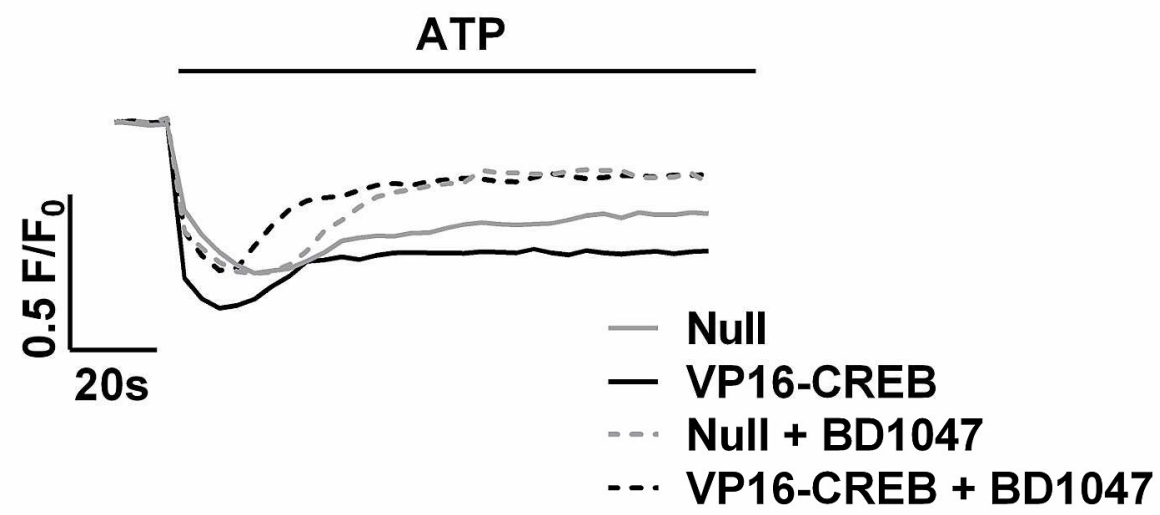

e

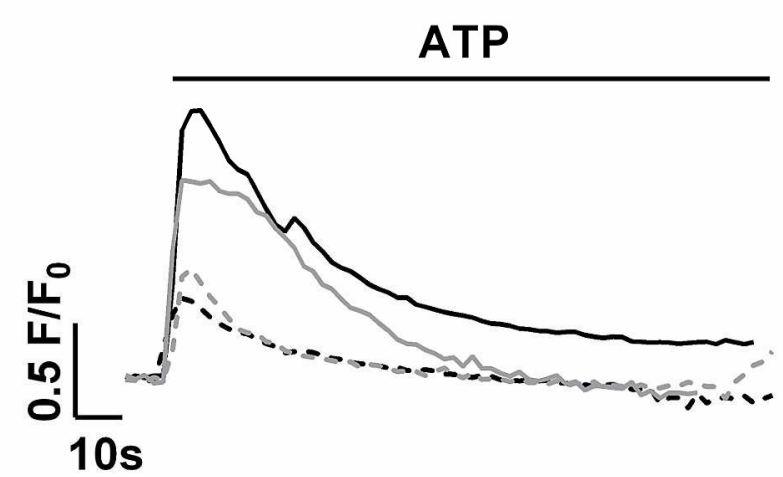

Null

VP16-CREB

-.. VP16-CREB + BD1047 b

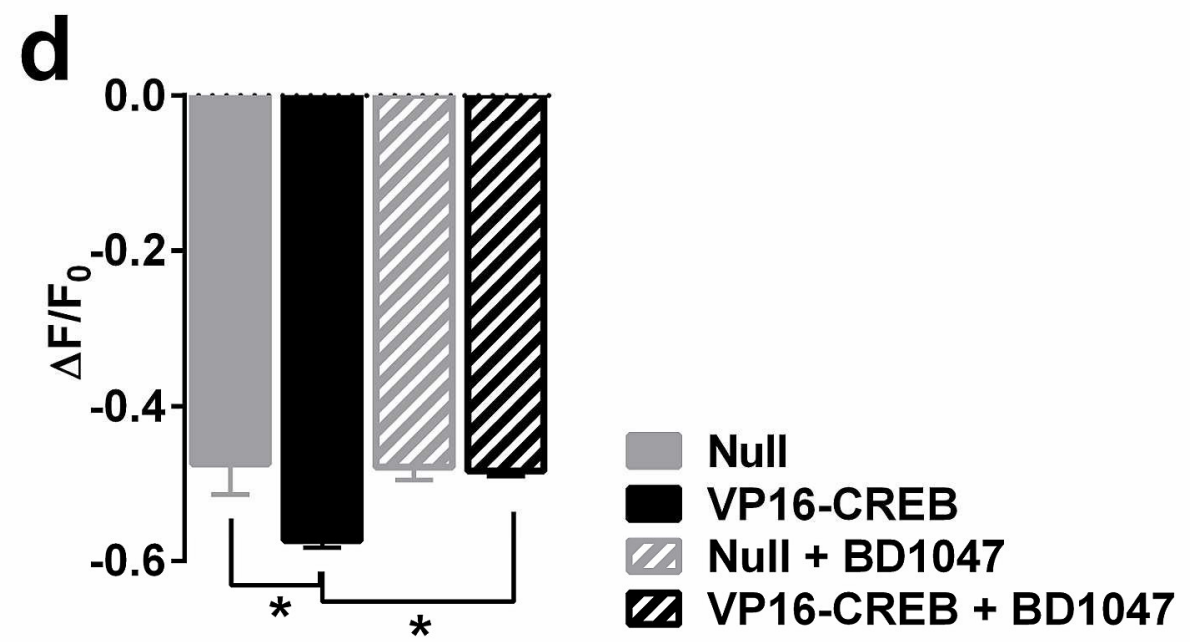

$f$

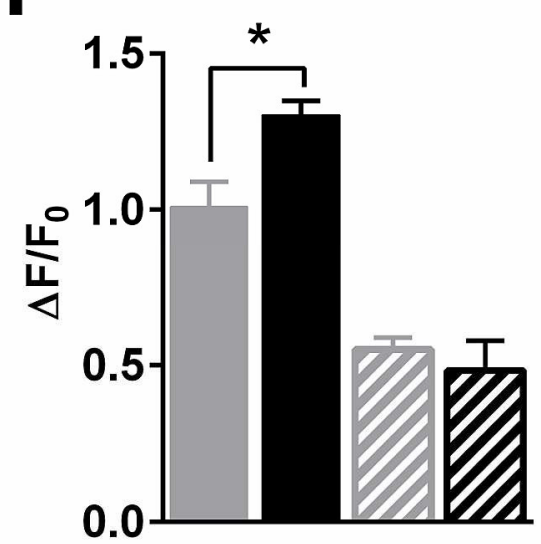


a

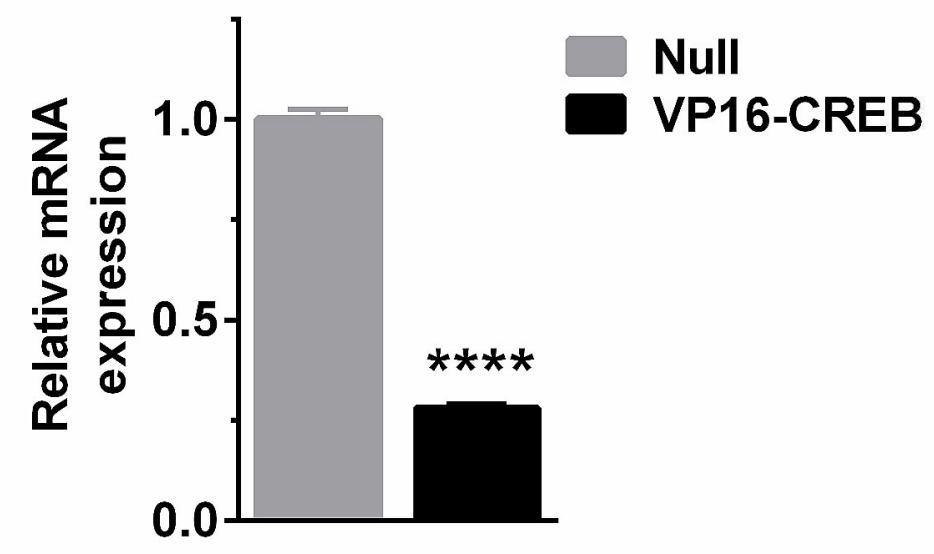

b

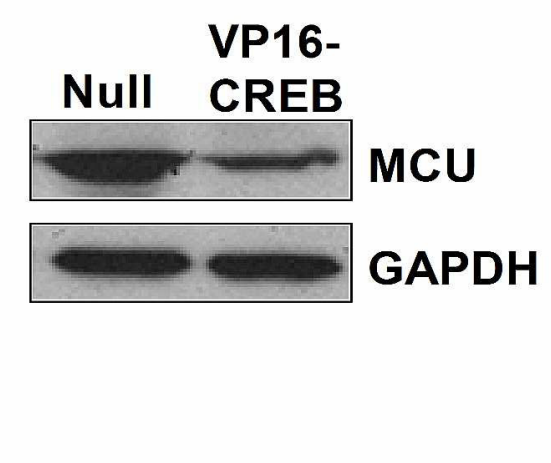



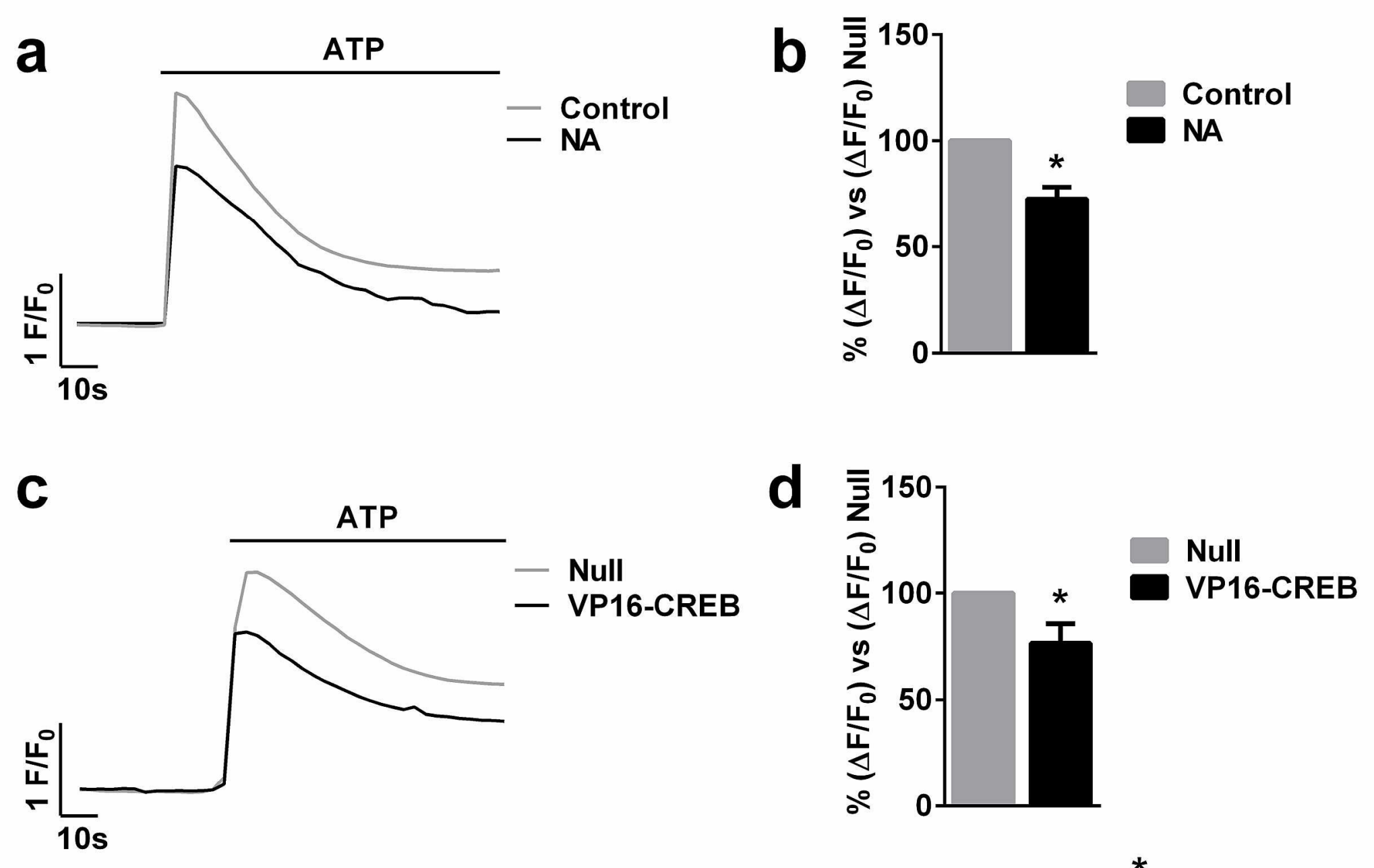

e
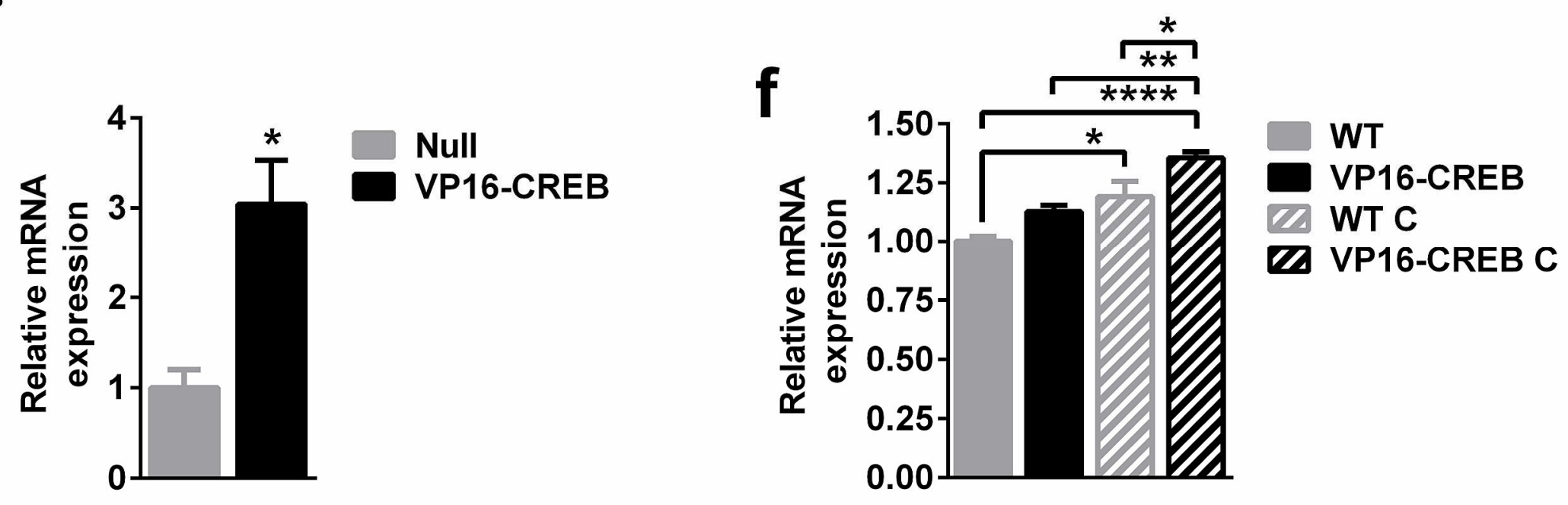


\section{Figure legends}

Fig. 1 Pre-stimulation with CREB-activating transmitters reduces transmitter-induced calcium responses. (a) Schematic representation of the protocol used. (b) Activation of CREB-dependent transcription by different transmitters measured with a luciferase gene-reporting assay. Control are cells not treated with any transmitter but with vehicle; otherwise cells were stimulated with $100 \mu \mathrm{M}$ ATP, $10 \mu \mathrm{M}$ noradrenaline (NA), $10 \mathrm{nM}$ endothelin-1 (ET-1), or $100 \mu \mathrm{M}$ glutamate (Glu) and CREB activity measured after 6 h. (c-h) Representative calcium traces (c, $\mathrm{e}, \mathrm{g}$ ) and quantification $(\mathrm{d}, \mathrm{f}, \mathrm{h})$ of maximum increases after the addition of $100 \mu \mathrm{M}$ ATP (c, d), $10 \mu \mathrm{M}$ NA (e, f), or $10 \mathrm{nM}$ ET-1 (g, h) after CREB activation with ATP, NA, ET-1 or Glu, identified with color codes. (*) P $<0.05$, $(* *) \mathrm{P}<0.01,(* * *) \mathrm{P}<0.001$.

Fig. 2. The transmitter-elicited reduction of cytosolic calcium responses is transient and CREB-dependent. Astrocytes were treated with $10 \mu \mathrm{M}$ NA to induce CREB activation. Representative traces of calcium responses induced by $100 \mu \mathrm{M}$ ATP at $12 \mathrm{~h}$ (a) and 24h (b) after CREB stimulation. (c) Quantification of peak calcium responses induced by ATP after 6, 12 and 24 hours after CREB stimulation. The data are the means \pm SEM of 3-4 independent experiments. (*) $\mathrm{P}<0.05,(* * *) \mathrm{P}<0.001$. (d-e) Representative $100 \mu \mathrm{M}$ ATP-induced calcium traces in single cells and (f) quantification of calcium responses after $6 \mathrm{~h}$ of stimulation of CREB with $10 \mu \mathrm{M}$ NA in Null and A-CREB infected astrocytes. The data are the means \pm SEM of 3-4 independent experiments. $(* *) \mathrm{P}<0.01$.

Fig. 3. VP16-CREB decreases calcium responses induced by transmitters. (a) VP16 immunocytochemistry and (b) western blot of VP16 in astrocytes infected with VP16-CREB or Null viral vectors. (c) Schematic representation of the protocol used to measured calcium responses in astrocytes infected with VP16-CREB or Null viral vectors. (d, f) Representative single cell traces of calcium responses induced by $100 \mu \mathrm{M}$ ATP (d) or $10 \mu \mathrm{M}$ NA (f) in VP16-CREB-infected astrocytes (virus MOI 1). (e, g) Quantification of peak calcium responses at different viral vector loads. Data are normalised for the response of Null-infected astrocytes at the same viral vector load. The data are the means \pm SEM of 4-7 (d) or 3-4 independent experiments (f) $\left(^{*}\right) \mathrm{P}<0.05$, (**)P $<0.01$.

Fig. 4. VP16-CREB action on calcium signalling pathways. ATP-elicited elevation of calcium was tested in astrocytes transducing VP16-CREB with no added calcium and presence of $0.5 \mathrm{mM}$ EGTA $\left(0 \mathrm{Ca}^{2+}\right)$, or in the presence of inhibitors of calcium release from acidic lysosomal-related stores: $50 \mu \mathrm{M}$ GPN or $100 \mu \mathrm{M}$ Ned-19. Control refers to cells without any treatment other than viral vector infection. Representative traces in single cells (a-c) and quantification (d) of $100 \mu \mathrm{M}$ ATP-induced calcium responses in Null and VP16-CREB-infected astrocytes. The data are the means \pm SEM of 6-8 independent experiments. $\left(^{*}\right) \mathrm{P}<0.05,(* *) \mathrm{P}<0.01$. (e) Representative images of astrocytes transfected with the ER calcium dye G-CEPIA1er before and after $100 \mu \mathrm{M}$ ATP application. Representative traces (f) and quantification (g) of the decrease in ER calcium. Data are means \pm SEM of 4 independent experiments. (***) $\mathrm{P}<0.001$.

Fig. 5. VP16-CREB increases mitochondrial calcium uptake. (a) Representative traces in single cells and (b) quantification of intracellular calcium responses induced by $100 \mu \mathrm{M}$ ATP in Null and VP16-CREB-infected astrocytes in astrocytes treated with FCCP to inhibit mitochondrial calcium uptake. The data are the means \pm SEM 
of 4 independent experiments. (c) Representative images of the astrocytes transfected with the mitochondrial calcium dye CEPIA3mt before and after $100 \mu \mathrm{M}$ ATP application. (d) Representative calcium traces and (e) quantification of $100 \mu \mathrm{M}$ ATP-induced mitochondrial calcium increase in Null and VP16-CREB-infected astrocytes. The data are the means \pm SEM of 4 independent experiments. $(* *) \mathrm{P}<0.01$.

Fig. 6. Sigma-1 receptor mediates the effects of VP16-CREB. (a) Quantification of sigma-1 receptor mRNA expression by quantitative PCR and (b) representative western blot of sigma-1 receptor in astrocytes infected with Null or VP16-CREB. (c) Representative calcium traces in single cells and (d) quantification of $100 \mu \mathrm{M}$ ATPinduced ER calcium decreases measured using G-CEPIAer in astrocytes infected with null or VP16-CREB viral vectors and in the absence and presence of BD1047, a sigma-1 receptor antagonist. (e) Representative calcium traces in single cells and (f) quantification of $100 \mu \mathrm{M}$ ATP-induced mitochondrial calcium increases using CEPIA3mt in astrocytes infected with Null or VP16-CREB viral vectors and in the absence and presence of BD1047. The data are the means \pm SEM of 3-4 independent experiments. $(*) \mathrm{P}<0.05$, (****) $\mathrm{P}<0.0001$.

Fig. 7. MCU expression decreases in VP16-CREB expressing astrocytes. (a) Quantification of MCU mRNA expression in Null and VP16-CREB-infected astrocytes by quantitative PCR (a) Data are the means \pm SEM of 3-4 independent experiments. (****) $\mathrm{P}<0.0001$. (b) Representative western blot of MCU in astrocytes infected by Null and VP16-CREB viral vectors.

Fig. 8. CREB decreases calcium responses and upregulates sigma-1 receptor in adult astrocytes. (a) Representative traces (b) and quantification of calcium responses induced by $100 \mu \mathrm{M}$ ATP after 6 hours of CREB stimulation (1 hour) with $10 \mu \mathrm{M}$ NA or vehicle (control). (c) Representative traces and (d) quantification calcium responses induced by $100 \mu \mathrm{M}$ ATP in adult cultured astrocytes infected with Null or VP16-CREB viral vectors. (e) Quantification of sigma-1 receptor mRNA expression by quantitative PCR in Null and VP16-CREB infected adult cultured astrocytes. In $(b, d, e)$ data are the means \pm SEM of 4 independent experiments. (*) $\mathrm{P}<0.05$. (f) Quantification by quantitative PCR of sigma-1 receptor mRNA expression in cortices in WT and VP16-CREB mice before (WT and VP16-CREB) and after cryolesion (WT C and VP16-CREB C). Cryolesions were performed to increase VP16-CREB expression in astrocytes conditional to gliosis. Data are the means \pm SEM of 4-5 animals in each condition. $(*) \mathrm{P}<0.05,(* *) \mathrm{P}<0.01,(* * * *) \mathrm{P}<0.0001$. 